\title{
¿Seasonal, Interannual, and Interdecadal Variations of the East Asian Summer Monsoon: A Diurnal-Cycle Perspective
}

\author{
GUIXING CHEN, ${ }^{\mathrm{a}, \mathrm{b}, \mathrm{c}}$ YU Du, ${ }^{\mathrm{a}, \mathrm{b}, \mathrm{c}}$ AND ZHIPING WEN ${ }^{\mathrm{d}, \mathrm{e}}$ \\ ${ }^{a}$ School of Atmospheric Sciences, Sun Yat-sen University, Zhuhai, China \\ ${ }^{\mathrm{b}}$ Key Laboratory of Tropical Atmosphere-Ocean System, Ministry of Education, Sun Yat-sen University, Zhuhai, China \\ ' Southern Marine Science and Engineering Guangdong Laboratory (Zhuhai), Zhuhai, China \\ ${ }^{\mathrm{d}}$ Department of Atmospheric and Oceanic Sciences, Fudan University, Shanghai, China \\ ${ }^{\mathrm{e}}$ Institute of Atmospheric Sciences, Fudan University, Shanghai, China
}

(Manuscript received 16 November 2020, in final form 16 February 2021)

\begin{abstract}
This study revisits the long-term variabilities of the East Asian summer monsoon (EASM) in 1958-2017 through examination of diurnal cycles. We group monsoon days into four dynamic quadrants (Q1 to Q4), with emphasis on the strong daily southerlies coupled with a large (Q1) or small (Q4) diurnal amplitude over Southeast China. The occurrence day of Q1 increases in June-July with the seasonal progress of the EASM. It is most pronounced in the 1960s to the 1970s and declines to the lowest in the 1980s to the 1990s, whereas the Q4 occurrence increases notably from the 1970s to the 1990s; both groups return to normal in recent years. The interdecadal decrease (increase) of Q1 (Q4) occurrence corresponds well to the known weakening of EASM in the twentieth century, and it also coincides with the rainfall anomalies over China shifting from a "north flooding and south drought" to a "north drought and south flooding" mode. The rainfall under Q1 (Q4) can account for $\sim 60 \%$ of the interannual variance of summer rainfall in northern (southern) China. The contrasting effects of Q1 and Q4 on rainfall are due to their remarkably different regulation on water vapor transport and convergence. The interannual/interdecadal variations of Q1 (Q4) occurrence determine the anomalous water vapor transports to northern (southern) China, in association with the various expansion of the western Pacific subtropical high. In particular, Q1 conditions can greatly intensify nighttime moisture convergence, which is responsible for the long-term variations of rainfall in northern China. The results highlight that the diurnal cycles in monsoon flow act as a key regional process working with large-scale circulation to regulate the spatial distributions and long-term variabilities of EASM rainfall.
\end{abstract}

KEYWORDS: Monsoons; Rainfall; Climate variability; Diurnal effects; Interannual variability; Interdecadal variability; Seasonal cycle

\section{Introduction}

A plentiful rainfall occurs over East Asia in the warm season due to the activities of the East Asian summer monsoon (EASM). Along with the seasonal progress of the EASM, the summer rainband marches northward in a stepwise manner, which is well known as the early-summer rainy season over southern China in May-June, the mei-yu-baiu season over central China and southern Japan from mid-June to mid-July, and the rainy season over northern China, the Korean Peninsula, and northern Japan in late July and August (e.g., Tao and Chen 1987; Chen et al. 2004; Ding and Chan 2005). At an interannual time scale, strong monsoon southerlies usually lead to positive rainfall anomalies in northern China, while weaker monsoon southerlies produce more rainfall in southern China. At an interdecadal time scale, the rainfall anomalies over China are shifted from a "north flooding and south drought" pattern to a "north drought and south flooding" pattern in the twentieth century when the monsoon southerlies are weakening ( $\mathrm{Wu}$ and Chen 1998; Wang 2001; Gong and Ho 2002; Zhai et al. 2005; Ding et al. 2008; Zhang 2015). In recent years, rainfall has begun

D Denotes content that is immediately available upon publication as open access.

Corresponding author: Dr. Guixing Chen, chenguixing@mail. sysu.edu.cn to increase in northern China plains with strengthening southerlies (Zhu et al. 2011). The long-term variabilities of EASM rainfall have been connected with the forcings such as the SSTA in oceans, snow cover, and aerosols over continents (Nitta and Yamada 1989; Zhang et al. 1996; Chang et al. 2000; Wu and Qian 2003; Ding et al. 2009; Duan et al. 2013; Song et al. 2014). For instance, the EASM variation at an interannual time scale is closely related to the Indian Ocean warming that often occurs after El Niño (Wu et al. 2009; Song and Zhou 2014a,b), whereas its change at decadal time scale may be related to the PDO (Zhou et al. 2013). The multiscale characteristics and processes of the EASM are an important scientific issue for understanding the regional climate and extreme weather.

Besides long-term variabilities, the winds and rainfall exhibit pronounced subdaily variations over Asia as a response to the diurnal cycle of solar radiation (e.g., Ohsawa et al. 2001; Wang et al. 2004; Yu et al. 2007; Chen et al. 2009; Yuan et al. 2012; Fujinami et al. 2017; Li et al. 2020a). Low-level southerlies tend to maximize at midnight or predawn, and their diurnal amplitude increases notably in the days when background monsoon flow is strong (Chen et al. 2013; Chen 2020). Monsoon southerlies strengthen water vapor transports and convergence after midnight, which is crucial for producing rainfall in the morning (Yamada et al. 2007; Chen et al. 2010; Xue et al. 2018; Pan and Chen 2019; Zhang et al. 2019; Zhang et al. 2020). Nocturnal monsoon southerlies also interact with other regional forcings, by which they regulate rainfall diurnal cycles across the EASM regions. For instance, the convergence of monsoon southerlies 
with land breeze or due to friction contrast helps to produce morning heavy rains at southern China coasts (X. Chen et al. 2017; Chen et al. 2018). The interactions of nocturnal monsoon southerlies with the mei-yu front and mesoscale convective vortices provide favorable conditions for generating persistent extreme heavy rains in central China (Sun and Zhang 2012; G. Chen et al. 2017; Zhang et al. 2018; Guan et al. 2020). Therefore, the diurnally varying processes in monsoon flow are regarded as a key factor regulating rainfall activities, which deserve studies to shed light on the climate in EASM regions.

The diurnal cycles of winds and rainfall exhibit long-term variations over East Asia, as regional forcings respond to the changes in large-scale conditions. The long-duration rainfall events with a morning peak related to MCSs exhibit an evident seasonal change and become dominant in summer over eastern China (Yu et al. 2007; Chen et al. 2010; Li et al. 2020b). These morning-peak rainfall events are particularly active in central China in the mei-yu period (Geng and Yamada 2007; Yuan et al. 2010, 2012), and they are shifted to northern China with the northward extension of diurnally varying monsoon flow in JulyAugust (Chen et al. 2013, 2014). At the longer time scales, the fraction of morning-hour rainfall decreases at northern China and increases at central China in the twentieth century, which is probably related to the weakening EASM (Yuan et al. 2013; Chen et al. 2014). Previous studies had documented that the long-term variations of EASM rainfall are attributed to the variations in daily/monthly mean of monsoon southerlies. There is still somewhat of a knowledge gap regarding subdaily variability of the EASM, particularly the mechanisms of diurnal cycles and their relationships to long-term variabilities. Further studies are needed to reveal the diurnal component of monsoon southerlies and its combined effects with the other components at daily or longer time scales on the regional climate over East Asia.

A recent study proposes a new method to estimate the intensity of the monsoon diurnal cycles over Asia (Chen 2020). Anomalies of the daily mean and diurnal amplitude in lowlevel southerlies are jointly used to categorize summer days into four dynamic groups. The four groups are distinguishable from each other in terms of their related large-scale circulations and moisture transports. In particular, strong daily southerlies with a large diurnal cycle are found to act as a largescale air pump that strengthens monsoon meridional circulation, transports moisture northward at night, and produces more morning rainfall. Such monsoon days are significantly different from the other monsoon days featuring strong daily southerlies but with a small diurnal cycle. The accumulative occurrence days of four groups in each summer also can be used to present the long-term variations of monsoon activities (Chen 2020). This method, taking both daily and diurnal components into account, provides a new prospective for studying the multiscale features of summer monsoon. Many previous studies have noted that the interannual/interdecadal variations of EASM rainfall are closely related to the moisture transports of monsoon flow at daily or longer time scales, which are regulated by the different modes of atmospheric circulations (e.g., Zhou and Yu 2005; Wu et al. 2009; Sun and Wang 2015; Hu et al. 2019; Zhou et al. 2020). To date, it is unclear how the monsoon southerlies with different diurnal cycles have changed in the past 60 years and how much they contribute to the long-term variations of rainfall patterns over East Asia through moisture transport.

In the present study, we examine the long-term variations of monsoon southerlies with different diurnal cycles using rainfall and atmospheric reanalysis data since 1958. The different modes of summer monsoon flow are compared to illustrate their influence on rainfall patterns and water vapor transports. The aim is to clarify the physical processes that are responsible for the long-term variabilities of EASM rainfall, for the first time, from a perspective of the diurnal cycle of monsoon flow. The rest of the article is presented as follows. Section 2 introduces the data used in this study. Section 3 shows the long-term series of the diurnal cycles of rainfall and low-level winds over East Asia in the past 60 years. Section 4 presents the occurrence of the different modes of monsoon flow and their related rainfall variabilities at seasonal, interannual, and interdecadal time scales. The water vapor transports by monsoon southerlies with different diurnal cycles are examined in section 5. Finally, conclusions and discussion are given in section 6.

\section{Data used in this study}

To describe atmospheric conditions, we use the Japanese 55yr global reanalysis (JRA-55), which is one of the longest series of reanalysis data from 1958 to the present (Kobayashi et al. 2015). JRA-55 provides a pressure-level product of 6-hourly assimilated atmospheric data at a grid spacing of $1.25^{\circ}$ longitude-latitude. It outperforms its predecessor in almost all aspects thanks to the improved model processes and data assimilation scheme. In particular, it has an excellent performance for representing the diurnal cycles of winds, temperature, and humidity over East Asia compared to the other mainstream reanalysis data (Chen et al. 2014). It also faithfully captures the spatial patterns and long-term variations of rainfall diurnal cycle, suggesting a good representation of moisture-related processes at a wide range of time scales. Meanwhile, we use a special version called JRA-55C, which is identical to JRA-55 except that only the conventional observation data are assimilated. Through comparison of JRA-55 and JRA-55C, we address whether the long-term change of diurnal cycles is affected by the assimilation of satellite data since the 1980s. We also use the recently released ERA5 hourly analysis (Hersbach et al. 2020) to examine whether the derived diurnal cycles and long-term variations of the EASM are dependent on reanalysis data or not. The diurnal cycle of any given variables is estimated by removing the daily mean. Following Chen (2020), the monsoon southerlies with different diurnal cycles are defined and categorized into four groups in section 4a.

To describe precipitation activities, we use rainfall estimate data from the Tropical Rainfall Measuring Mission (TRMM $3 \mathrm{~B} 42 \mathrm{v} 7$ ). It provides 3-hourly rain rate at a grid spacing of $0.25^{\circ}$ longitude-latitude, which has been calibrated by rain gauge monthly records (Huffman et al. 2007). TRMM is available since 1998 and gives high-resolution rainfall both on land and over ocean. It represents well the complex spatial patterns and long-term variations of rainfall diurnal cycle over East Asia, consistent with rain gauge observations (e.g., Zhou et al. 2008; Chen et al. 2018). To describe the interannual and interdecadal variations of rainfall, we also use the Asian 

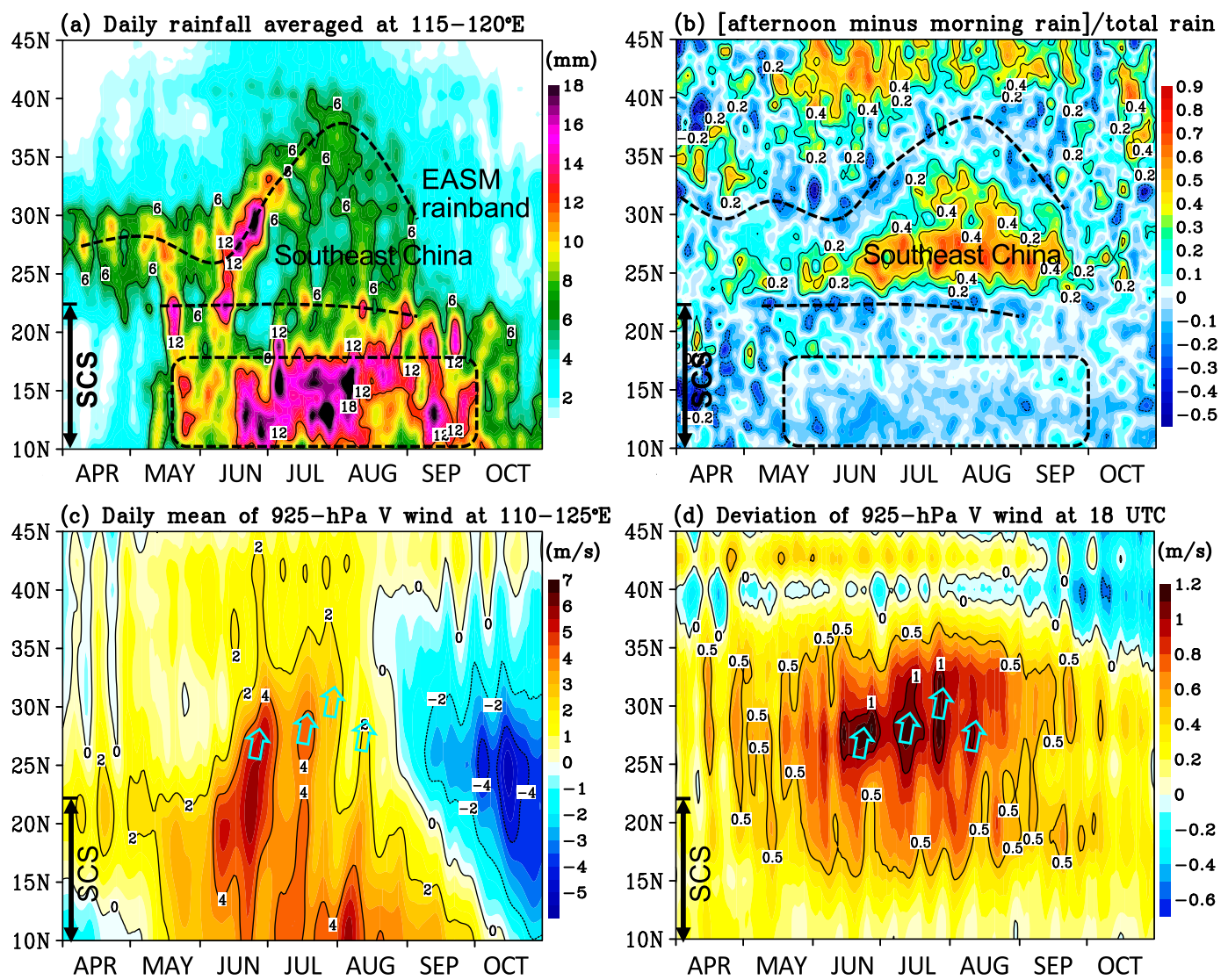

FIG. 1. Seasonal change of rainfall, low-level meridional wind, and their diurnal variations over East Asia. (a) Daily rainfall amount averaged in 1998-2017 in TRMM 3B42, (b) diurnal difference of rainfall between afternoon and morning hours (shading in blue for prevalent morning rainfall), (c) daily mean meridional wind at $925 \mathrm{hPa}$ in JRA-55, and (d) diurnal deviation of 925-hPa meridional wind at 1800 UTC (0200 LST). The dashed lines and rectangles in (a) and (b) denote the major rainy seasons over East Asia, southern China coasts, and South China Sea (SCS). The arrows in (c) and (d) denote the subseasonal enhancement of southerly wind in both daily mean and diurnal amplitude over Southeast China.

Precipitation-Highly Resolved Observational Data Integration toward Evaluation of Water Resources (APHRODITE). It provides a long-term (from 1951 onward) daily gridded precipitation dataset for Asia based on a very dense network of rain gauges (Yatagai et al. 2012). The high-quality version designed for the Asian monsoon regions at a grid spacing of $0.25^{\circ}$ longitude-latitude is used in this study. It is highly consistent with rain gauge observations in capturing the long-term trends of rainfall amount over China (Han and Zhou 2012).

\section{Long-term series of rainfall and winds over East Asia in the past 60 years}

\section{a. Seasonal change of rainfall, southerly wind, and their diurnal variations}

Figures 1a and 1c show the latitudinal-seasonal distribution of daily-mean rainfall and low-level southerlies over East Asia and the South China Sea (SCS). In the central SCS at $10^{\circ}-18^{\circ} \mathrm{N}$, rainfall intensifies after mid- to late May with enhanced southerlies of monsoon onset. Rainfall is also substantial at the coasts of southern China near $\sim 22.5^{\circ} \mathrm{N}$ from mid-May to midJune because of convergent monsoon southwesterlies, and it resumes in late July and August due to tropical disturbances. Over the continent, the EASM rainband marches northward with monsoon southwesterlies at mid- to late June (referred to as mei-yu in Chinese, baiu in Japanese, or changma in Korean). At late July and early August, the rainband reaches north of $35^{\circ} \mathrm{N}$. Both rainfall and southerlies decline rapidly in September over East Asia and retreat to the SCS where they gradually weaken in October. So, we see a large seasonal change in the daily rainfall and winds in the EASM regions (e.g., Chen et al. 2004; Ding and Chan 2005).

Figures $1 \mathrm{~b}$ and $1 \mathrm{~d}$ show the corresponding seasonal change of the diurnal variations in rainfall and low-level southerly wind. The strong rainfalls in the central SCS, the coasts of southern China, and the East Asian rainband mostly occur in the morning (0000-1200 LST), while the rainfall over Southeast China (SEC) is dominant in the afternoon (12002400 LST) (Fig. 1b). Along with the progress of the EASM 
rainband since mid-June, the morning-peak rainfall marches northward and the afternoon-peak rainfall extends on land of SEC. Meanwhile, the diurnal deviation of southerly wind at 0200 LST becomes most pronounced at SEC in JJA (Fig. 1d). The maximum diurnal amplitude of southerly wind exceeds $1 \mathrm{~m} \mathrm{~s}^{-1}$ at $\sim 27^{\circ} \mathrm{N}$, suggesting an enhanced diurnal cycle in the warm season (Chen 2020). At subseasonal time scale, wind diurnal variation intensifies at mid-June and extends northward since mid-July (arrows in Fig. 1d), which coincides with the progress of background southerlies (arrows in Fig. 1c). Nocturnal southerly wind exhibits a large meridional gradient at the EASM rainband with a prevalent morning peak, implying a regulation on rainfall diurnal cycle (Figs. 1b,d). Therefore, the diurnal variations of rainfall and low-level winds undergo a remarkable seasonal change over East Asia, which can be regarded as a key component of the EASM system (Chen et al. 2009, 2013; Johnson 2011; Yuan et al. 2012; Chen 2020).

\section{b. Interannual/interdecadal variations of the summer rainfall and low-level winds}

Figure 2a shows the interannual variation of JJA rainfall over East Asia. Strong rainfall of more than $800 \mathrm{~mm}$ is observed south of $25^{\circ} \mathrm{N}$. Rainfall is also substantial in the mei-yu rainband near $30^{\circ} \mathrm{N}$, while it is relatively small north of $35^{\circ} \mathrm{N}$. Rainfall amount varies from year to year at all latitudes, indicating a large interannual variability. Figure $2 b$ further shows the interannual and interdecadal variations of normalized rainfall (i.e., the rainfall anomaly relative to JJA-mean climatology). Positive rainfall anomalies mainly appear north of $35^{\circ} \mathrm{N}$ during the 1960 s and the $1970 \mathrm{~s}$, whereas they are shifted southward to $28^{\circ}-35^{\circ} \mathrm{N}$ in the 1980 s. During $1993-2002$, the positive rainfall anomalies are displaced farther south to SEC (south of $30^{\circ} \mathrm{N}$ ) (Kwon et al. 2007). Rainfall patterns thus undergo an interdecadal change from a "north flooding and south drought" mode to a "north drought and south flooding", mode at the end of the 1970s (e.g., Si et al. 2009; Ding et al. 2008). Figure $2 \mathrm{~b}$ also shows that positive rainfall anomalies recently tend to move northward to the Huang-Huai River region $\left(32^{\circ}-36^{\circ} \mathrm{N}\right)$ during $2003-11$ compared to $1979-2002$, as also in Zhu et al. (2011). These interdecadal variations in summer rainband are connected with the major events of flooding or drought over East Asia (Zhai et al. 2005; Ding et al. 2008; Chen and Zhai 2013).

Figure $2 \mathrm{c}$ shows the variations of low-level meridional wind in past 60 years. The southerly wind is dominant and exhibits large variations over SEC at $23^{\circ}-29^{\circ} \mathrm{N}$. It is strong in the $1960 \mathrm{~s}$ and early $1970 \mathrm{~s}$, with a JJA mean of $2.5 \mathrm{~m} \mathrm{~s}^{-1}$ extending to $\sim 32^{\circ} \mathrm{N}$. In the 1980 s and early 1990 s, the southerly wind becomes weak and the intensity of $2.5 \mathrm{~m} \mathrm{~s}^{-1}$ is mostly located south of $30^{\circ} \mathrm{N}$, implying an interdecadal weakening of summer monsoon flow (Wang 2001; Ding et al. 2008, 2018). It is active in southern China for some years from the early 1990s to the early 2000s, while it is generally weak in northern China. The southerly wind becomes above normal in most years during 2003-13. To facilitate further analysis, we denote the intensities of monsoon flow using the low-level meridional wind averaged over SEC, as in previous studies (Zhang et al. 1996; Wang and Fan 1999; Ding and Chan 2005; Chen 2020).
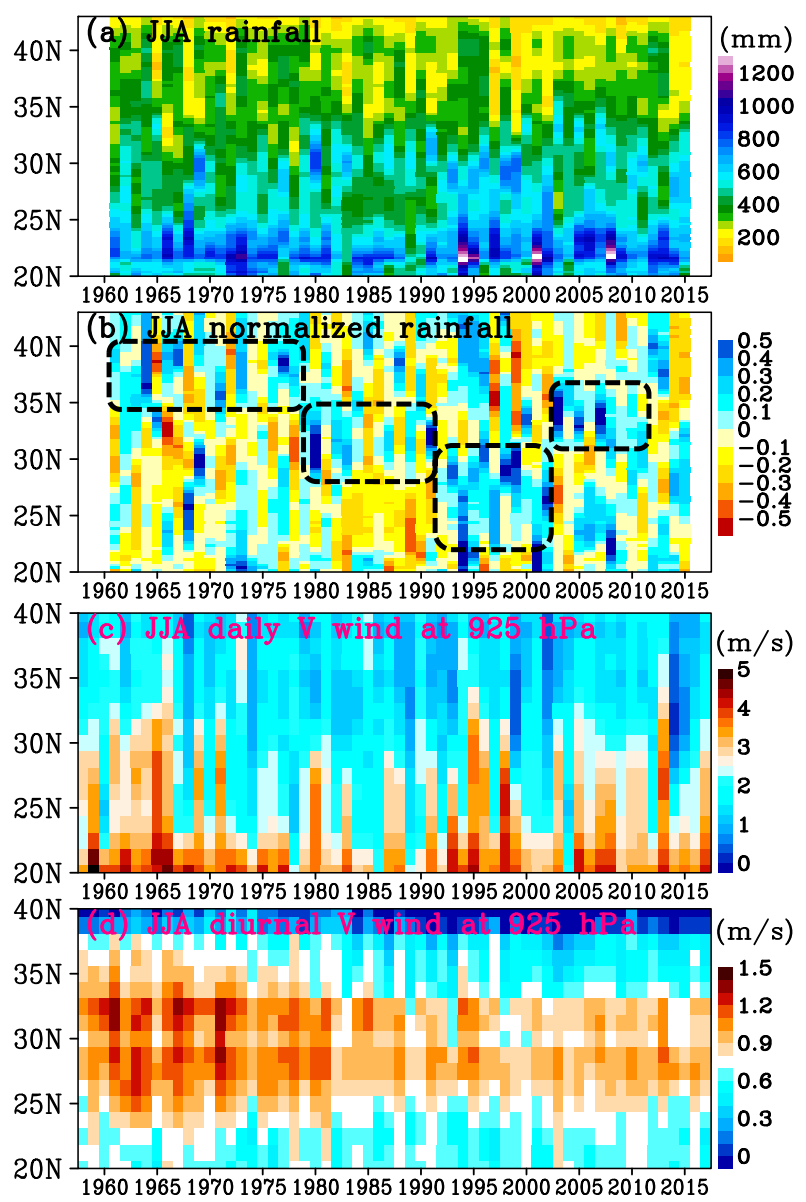

FIG. 2. Long-term variations of (a) summer rainfall in APHRODITE, (b) normalized rainfall anomaly, (c) low-level southerly wind in JRA-55, and (d) southerly wind diurnal amplitude averaged over $108^{\circ}-125^{\circ} \mathrm{E}$. In (b), the dashed rectangles denote the decadal periods with positive rainfall anomalies.

Figure 3a further shows that the time series of daily southerlies averaged in SEC undergoes a long-term weakening from the 1960 s to the early 1990 s and a strengthening in the recent two decades. The weakening southerlies in the twentieth century are accompanied by the southward shift of rainfall anomalies (Fig. 2b), while the recent intensification corresponds to the increasing rainfall in the Huang-Huai River region (Si et al. 2009; Zhu et al. 2011). Overall, the intensity of southerlies over SEC is roughly proportional to the rainfall amount in northern China at $32^{\circ}-37^{\circ} \mathrm{N}$, with a correlation coefficient of $0.23-0.3$, exceeding the $90 \%$ confidence level. These features suggest that the long-term variations of monsoon southerlies play a key role in regulating the EASM rainband. Many previous studies further decomposed monsoon circulation into several principal patterns to clarify the physical processes and external forcings that govern the long-term variability of rainfall (e.g., Zhou and Yu 2005; Ding et al. 2009; Wu et al. 2009; Hu et al. 2019).

Figure $2 \mathrm{~d}$ shows the variations of the diurnal amplitude of southerly wind over East Asia in the past 60 years. The diurnal 
(a) JJA 925-hPa southerly wind at Southeast China

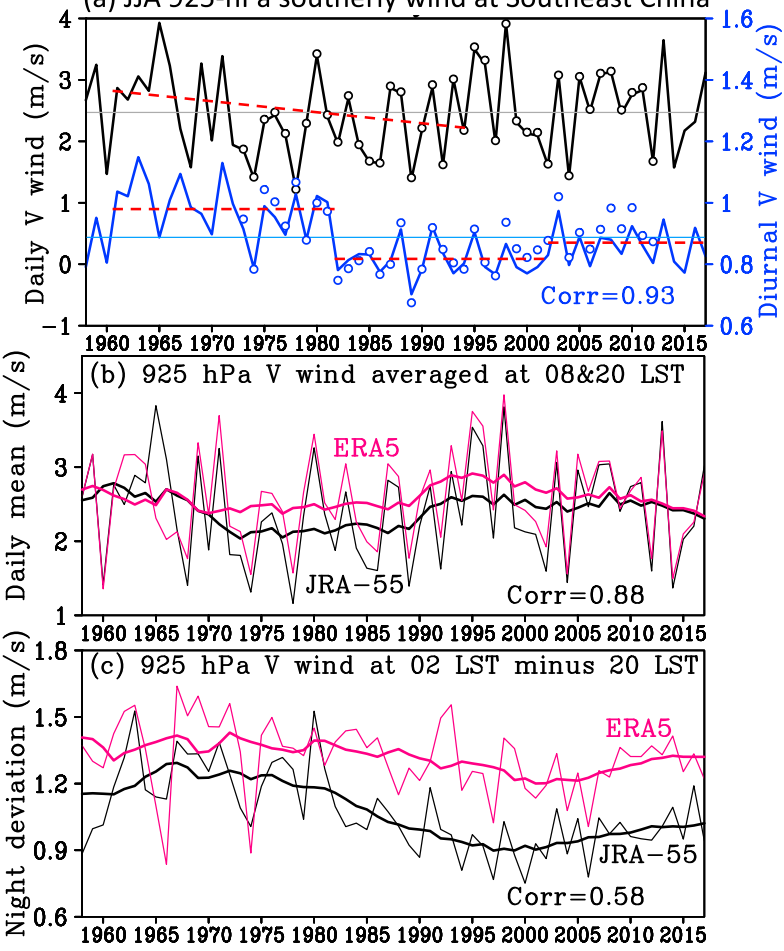

FIG. 3. (a) Interannual variations of southerly monsoon in terms of daily mean (black line) and diurnal amplitude (blue line) over Southeast China $\left(23^{\circ}-29^{\circ} \mathrm{N}, 110^{\circ}-125^{\circ} \mathrm{E}\right)$ derived from JRA-55. The open circles denote the values of JRA-55C with conventional observation data assimilated. The correlation coefficient of diurnal amplitude between JRA-55 and JRA-55C is marked at the bottom right. The dashed lines approximately denote the decadal trends. (b) Daily southerly wind averaged at 0800 and 2000 LST over Southeast China in ERA5 and JRA-55. (c) Diurnal deviation of southerly wind at 0200 LST minus the preceding 2000 LST. The bold solid lines in (b) and (c) denote the decadal series with a running mean of 11 years.

amplitude is relatively large in the 1960s and 1970s, whereas it becomes small since the early 1980 s. So, we can see an interdecadal weakening in the monsoon southerlies, for the first time, in terms of their diurnal cycle. Figure $2 \mathrm{~d}$ also shows that wind diurnal amplitude has two maxima at $23^{\circ}-29^{\circ}$ and $31^{\circ}-$ $33^{\circ} \mathrm{N}$, with similar interannual and interdecadal variations. As the maximum over SEC at $23^{\circ}-29^{\circ} \mathrm{N}$ persists through JJA (Fig. 1d), it can be used to denote the intensity of diurnal cycle of monsoon southerlies. Figure 3 a shows that the wind diurnal amplitude has an average of $\sim 0.9 \mathrm{~m} \mathrm{~s}^{-1}$, which is comparable to $\sim 40 \%$ of daily mean. The diurnal amplitude is above normal in most years of 1958-81, whereas it is mainly below normal during 1982-2002 and seems to return to a normal level in the recent years after 2003. The large diurnal amplitude of southerlies in the 1960 s to 1970 s corresponds to the north-displaced rainband, despite some decreases in daily southerlies in the 1970s. The interdecadal weakening of EASM southerlies since the early 1980s is much more evident in the diurnal variation than in the daily mean (Fig. 3a), which coincides with the southward displacement of the rainband (Fig. 2b). Overall, the JJA-mean intensity of southerly diurnal variation is closely related to the rainfall amount in northern China, with a correlation coefficient of $\sim 0.33$, above the $95 \%$ confidence level. Such a linkage indicates that the diurnal component of monsoon flow may also play a key role in the long-term variabilities of EASM rainfall.

To clarify whether the long-term variations of southerlies in JRA-55 are subject to the assimilation of observations particularly satellite data, we estimate the variations using JRA-55C in which only the conventional data are assimilated. Figure $3 \mathrm{a}$ shows that the difference of daily-mean southerlies between JRA-55 and JRA-55C is almost negligible. The diurnal amplitude also has a little difference before 1997, whereas the amplitude in JRA-55 becomes slightly smaller than that in JRA-55C in the recent 20 years. Nevertheless, the time series of two datasets are highly similar through the period of study. Therefore, we consider that the long-term variation of diurnal amplitude in JRA-55 is not affected much by the change in observation data sources.

We also evaluate the low-level winds using the hourly analysis data of ERA5. The southerly wind over SEC is shown to have a sharp decrease between 1700 and 1800 LST (0500 and 0600 UTC) (figure not shown), because ERA5 uses the $12-\mathrm{h}$ windows of $4 \mathrm{D}-\mathrm{Var}$ data assimilation. For a better comparison between different reanalysis data, it is viable to calculate the daily mean as an average at the synoptic hours 0800 LST (0000 UTC) and 2000 LST (1200 UTC) when the rawinsonde data are assimilated, and to estimate the diurnal deviation as an increase from 2000 LST to the following 0200 LST in the same assimilation window. Figures $3 \mathrm{c}$ and $3 \mathrm{~d}$ show that ERA5 usually gives the daily mean and diurnal deviation larger than JRA-55 except in a few abnormal years (1965, 1966, and 1974). Apart from these issues, ERA5 has a good agreement with JRA-55 in representing the long-term variations of monsoon southerlies in terms of both daily and diurnal components (Figs. 3c,d), with correlation coefficients above the $99.9 \%$ confidence level. Considering this consistency, we mainly present the results from JRA-55 in this study.

Figure $3 \mathrm{a}$ also shows that the interannual variation of southerly diurnal amplitude is roughly correlated with the daily wind speed, with a correlation coefficient of 0.35 . The large diurnal cycle of low-level winds seems to occur preferentially in the strong monsoon flow (Chen et al. 2009, 2013; Shapiro et al. 2016; Xue et al. 2018). The wind diurnal amplitude is also affected by the other regional factors such as the turbulent mixing due to daytime heating in the ABL (Chen 2020). In the following sections, we examine how the daily and diurnal components of monsoon southerlies jointly regulate the longterm variabilities of rainfall over East Asia.

\section{The EASM diurnal cycle and its impacts on summer rainfall}

\section{a. Categories of the EASM diurnal cycle}

To clarify the processes that govern the EASM rainband, we focus on the low-level meridional wind at its adjacent south. 
We select $\operatorname{SEC}\left(23^{\circ}-29^{\circ} \mathrm{N}, 110^{\circ}-125^{\circ} \mathrm{E}\right)$ as the key region where the 925 -hPa southerlies in terms of both daily mean and diurnal amplitude are pronounced (Figs. 1-3) and strongly affect the rainfall of EASM summer rainband (Figs. 5b,d in Chen 2020). A strong (weak) background monsoon flow can be defined when the daily mean southerly component over SEC at a given day is above (below) the climate mean of $2.45 \mathrm{~m} \mathrm{~s}^{-1}$. About half of the summer days are categorized as strong monsoon days and half as weak monsoon days, which is consistent with previous studies. Both strong and weak monsoon days are found to usually last for several days or even weeks, in an association with intraseasonal/interannual variations, thereby denoting the large-scale atmospheric conditions. The diurnal variations of low-level winds over SEC are found to exhibit a phase-locked clockwise rotation, with a maximum of southerly component at 0200 LST (Chen et al. 2009; Chen et al. 2010). The diurnal amplitude is mainly determined by the daytime heating in PBL over landmass, thereby denoting the regional forcings at shorter time scales (Chen 2020). A large (small) diurnal cycle can be identified when the diurnal southerly deviation at 0200 LST of any given day is above (below) the climate deviation of $0.90 \mathrm{~m} \mathrm{~s}^{-1}$.

Based on the anomalies of daily mean and diurnal amplitude described above, a total of 5520 summer days in past 60 years can be grouped into four quadrants (Q1-Q4; i.e., strong or weak background monsoon flow with a large or small diurnal amplitude). As in the scatterplot of Fig. 7c in Chen (2020), the quadrants to the right (Q1 and Q4) denote the strong monsoon days with above-normal daily southerlies, while those to the left (Q2 and Q3) denote the weak monsoon days. The upper quadrants (Q1 and Q2) have a large diurnal cycle of southerlies with an above-normal amplitude, while the bottom ones (Q3 and Q4) have a small diurnal cycle. The occurrence of Q1 days is about 1.5 times that of Q4 days (and analogously for Q3 days vs Q2 days), as strong monsoon flows are relatively favorable for the enhanced diurnal cycle (Chen et al. 2009, 2013; Chen 2020). These four groups of diurnal monsoon variability (DMV) represent the different properties of monsoon flow and associated influence on rainfall, which are statistically distinguishable from each other (Chen 2020). Given the importance of strong monsoons and to keep the interpretation concise, we pay more attention to the Q1 and Q4 groups for clarifying the roles of different diurnal cycles under strong monsoons in the long-term variations of East Asian climate.

\section{b. Seasonal, interannual, and interdecadal variations of the EASM diurnal cycle}

Figure 4a shows the monthly occurrence days of four DMV groups averaged in 1958-2017. The occurrence of strong daily southerlies (Q1 and Q4) is about 10 days in April and May, whereas it increases remarkably to 17 days in June and to 22 days in July after the onset of SCS summer monsoon. Among them, about 10 days in June and 15 days in July are regarded as the strong southerlies with a large diurnal amplitude (Q1), implying a pronounced monsoon flow at night. The features correspond to the observed frequencies of nocturnal low-level jets that increase considerably from April-May to (a) Occurrence of four quadrants of EASM diurnal cycles
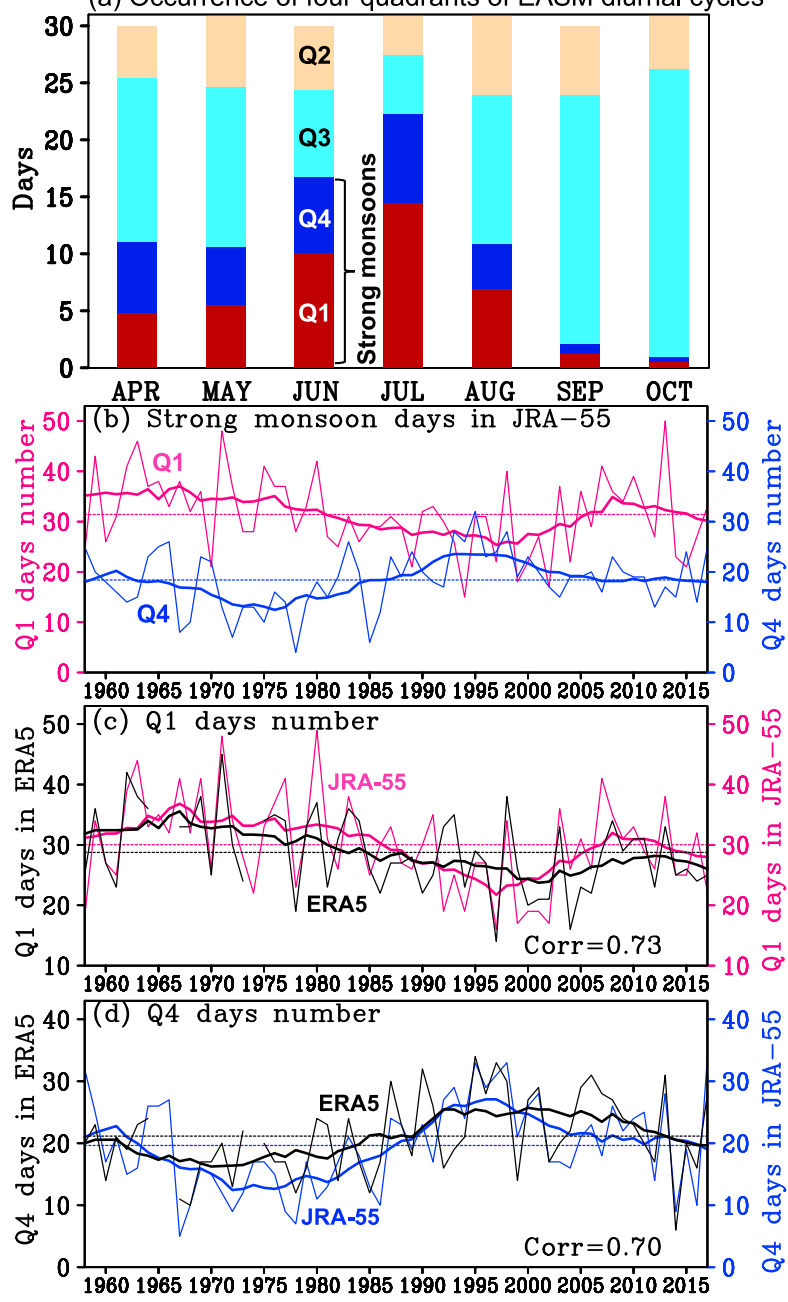

FIG. 4. (a) Seasonal variation of the occurrence of four quadrants of EASM diurnal cycles. (b) Interannual/interdecadal variations of the occurrence days of strong monsoon southerlies with a large (Q1) or small (Q4) diurnal cycle derived from JRA-55. (c),(d) As in (b), but categorized using the daily mean averaged at 0800 and 2000 LST and the diurnal deviation at 0200 LST minus the preceding 2000 LST, with three abnormal years $(1965,1966$, and 1974) in ERA5 removed. The bold solid lines in (b)-(d) denote the decadal series with a running mean of 11 years.

June-July over SEC (Du and Chen 2019). In August, the occurrence of strong monsoons declines to 11 days, with 7 days of Q1 group. The occurrence days of southerlies almost disappear in September and October when the summer monsoon has retreated. Therefore, the seasonal change of four DMV groups, from the joint perspective of daily and diurnal components, represents well the activities of monsoon flows over East Asia (Figs. 1c,d).

Figure $4 \mathrm{~b}$ shows the long-term variations of Q1 and Q4 occurrences during JJA in past 60 years. The Q1 (Q4) occurrence has a climate mean of about 31 (19) days. The Q1 (Q4) occurrence has a minimum of 15 (4) days and a maximum of 50 
(a) JJA

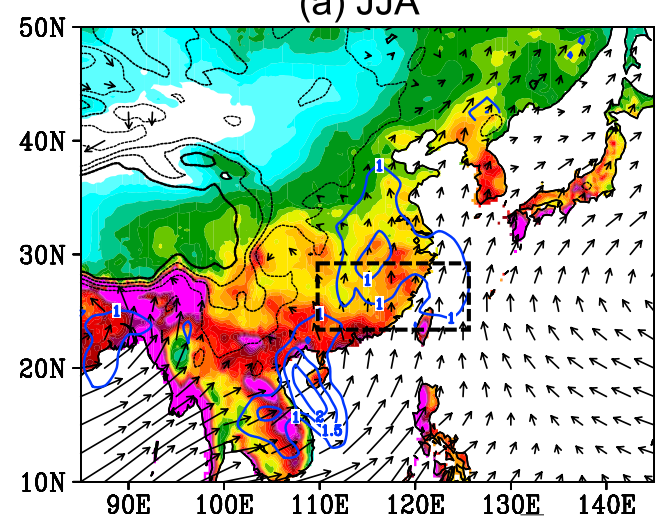

(c) Q3

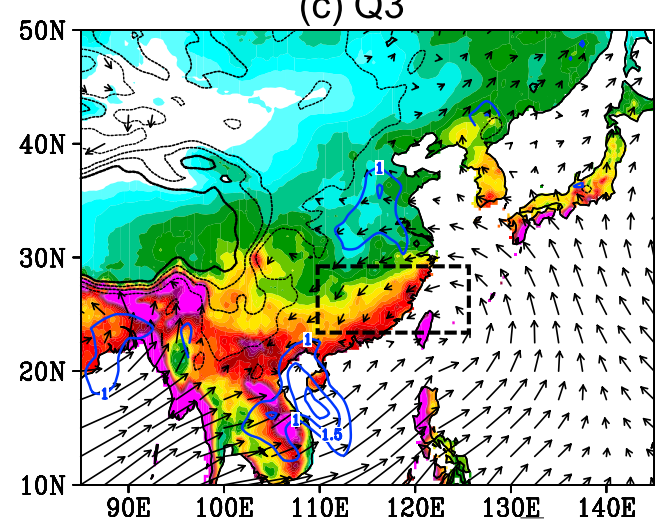

(b) Q1

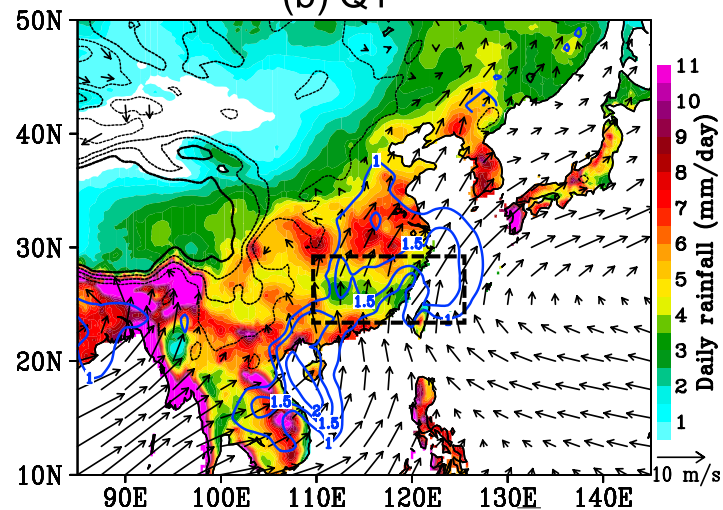

(d) Q4

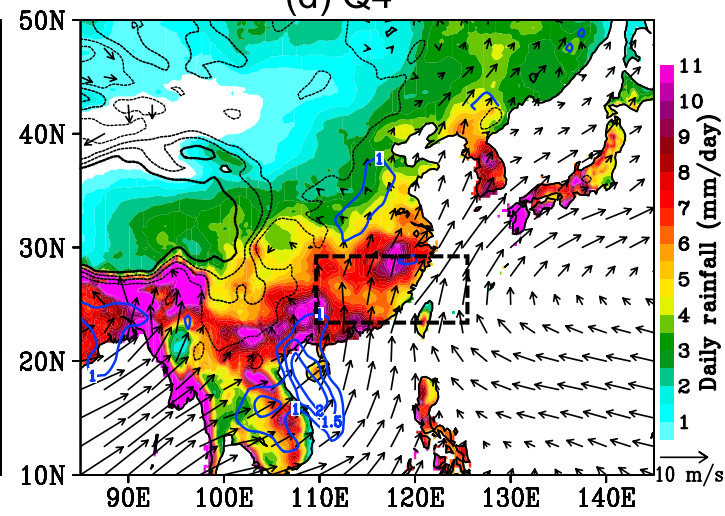

FIG. 5. Spatial patterns of the daily mean rainfall (shading), 925-hPa winds (vectors), and the diurnal deviation of southerly wind at 1800 UTC (blue contours for $>1 \mathrm{~m} \mathrm{~s}^{-1}$ ) for (a) the JJA mean and (b) Q1, (c) Q3, and (d) Q4. The black dashed lines denote the elevation at an interval of $1000 \mathrm{~m}$. The dashed rectangles denote the domain of Southeast China.

(32) days, showing large interannual variations. They also exhibit an evident interdecadal variation as shown by the bold lines. The Q1 occurrence is highest in the 1960s to the 1970s with a decadal average of $\sim 35$ days, but it decreases significantly in the 1980s to the 1990s to the lowest average of $\sim 26$ days. The shift from positive to negative anomalies occurs approximately at the early 1980s. Such an interdecadal decrease of Q1 occurrence corresponds to the well-known weakening of summer monsoon over East Asia in the twentieth century. The Q1 occurrence increases in the first 10 years of the twenty-first century, implying a recovery of EASM diurnal cycle. As a comparison, the Q4 occurrence is the lowest ( $\sim 14$ days) in the 1970s, increases notably in the 1980s, becomes the highest ( $\sim 24$ days) in the 1990s, and returns to normal in the recent years. This interdecadal change of Q4 is nearly opposite to that of Q1, with a correlation coefficient of -0.65 . It has an amplitude of 9-10 days, which is comparable to that of Q1. There is a dramatic shifting between the two types of EASM diurnal cycles in the past 60 years, although the change in the total of strong monsoon days is relatively small. The difference between Q1 and Q4 is as large as $\sim 20$ days in the 1970 s, declines to $\sim 4$ days in the 1990 s, and recently has returned to $\sim 14$ days. Therefore, the strong monsoon southerlies with different diurnal cycles are characterized by the remarkably different interdecadal variations, which shed light on the long-term change of regional climate. The long-term variations of Q1 and Q4 occurrences are also seen in ERA5, and are highly correlated with those in JRA-55 (Figs. 4c,d), and thus they are a robust signal and not reanalysis dependent. The interdecadal change in weak monsoons (Q2 and Q3) is not so evident (figure not shown).

\section{c. Rainfall patterns associated with the EASM diurnal cycle}

We examine the spatial patterns of summer rainfall associated with monsoon flow and its diurnal variation through comparison of different DMV groups. In a climatological mean, the monsoon southwesterlies dominate the Bay of Bengal, the Indochina Peninsula, and the South China Sea, while the southeasterlies prevail over the tropical western Pacific (Fig. 5a). These two flows are confluent over SEC and turn northward, so that the moist southerlies produce abundant rainfall over East Asia (e.g., Ding and Chan 2005). In the days with the strong southerlies over SEC and an anticyclonic 
pattern over northwestern Pacific, the rainfall intensifies in the subtropical areas of East Asia (Figs. 5b,d). In the days with the suppressed southerlies over SEC particularly with a cyclonic pattern in the northern SCS, rainfall instead remains in the tropics and the coasts of SEC (Fig. 5c).

Figures $5 \mathrm{~b}$ and $5 \mathrm{~d}$ also show that rainfall patterns over China have an evident regional difference between Q1 and Q4 with different diurnal amplitudes of southerlies, although the daily mean southerlies have similar patterns and strength $\left(\sim 4.8 \mathrm{~m} \mathrm{~s}^{-1}\right)$. In Q1 days with strong southerlies at a large diurnal cycle over SEC, rainfall is most pronounced in northern China plains at $30^{\circ}-35^{\circ} \mathrm{N}$ (Fig. 5b) and mainly occurs in morning hours. In Q4 days with strong southerlies but at a small diurnal cycle, the rainfall is mostly confined south of $30^{\circ} \mathrm{N}$ (Fig. 5d). The rainfall in Q4 mostly occurs in daytime, so that the associated cloudy condition may lead to a small diurnal cycle of low-level winds (Chen 2020). Therefore, the strong monsoon flows coupling with a large (small) diurnal cycle correspond well to the rainfall in the northern (southern) regions of East Asia. These distinct differences among the DMV groups highlight that not only can the background monsoon flow strongly affect the overall patterns of summer rainfall, but also its diurnal component is closely related to the regional features.

In the climate-mean perspective, as the occurrences of four DMV groups undergo different monthly variations, their associated rainfall patterns somewhat correspond to the shifting of rainy seasons over East Asia. The Q4 group occurs in the early summer when rainfall is mainly located in SEC (Figs. 4a and 5d). The Q1 occurrence increases considerably from June to July when the EASM rainband shows a northward progress to central and northern China (Figs. 4a and 5b). In contrast, the Q3 occurrence increases from August to October when the landfall of tropical cyclones tends to produce rainfall at coastal areas (Figs. 4a and 5c). The shifting of four DMV groups thus seems to play a role in the subseasonal progress of rainfall patterns (Fig. 1; Yuan et al. 2010), which deserves further analysis in the future. In this study, we focus on the accumulative days of Q1 and Q4 occurrences in JJA, which denote an overall intensity of two major modes of the EASM in each year. As they vary largely in years and even decades (Fig. 4b), their contribution to the longterm variations of regional climate can be estimated.

\section{d. Interannual/interdecadal variations of rainfall associated with EASM diurnal cycle}

To clarify the role of DMV in the long-term variations of rainfall, we decompose the rainfall amount of each summer into the parts associated with four DMV groups. Figure 6a shows that the rainfall related to Q1 is pronounced north of $30^{\circ} \mathrm{N}$ in most of the years, while it is relatively weak near $25^{\circ} \mathrm{N}$. The Q1related rainfall is also strong at $35^{\circ}-40^{\circ} \mathrm{N}$ from the 1960 s to 1970 s, whereas it is mainly confined to $30^{\circ}-35^{\circ} \mathrm{N}$ in $1979-91$ and 2003-11, suggesting a large change at interdecadal time scale. The rainfall at $30^{\circ}-35^{\circ} \mathrm{N}$ also exhibits an evident interannual variation, with the maxima in 1969, 1980, 1991, 2003, 2005, and 2007. The Q1-related high rainfall in these years corresponds to the large anomalies of summer total rainfall (cf. Figs. 6a and 2b). Overall, the rainfall amount related to Q1 group ( $\sim 34 \%$ of summer days) accounts for $\sim 50 \%$ of the summer total rainfall

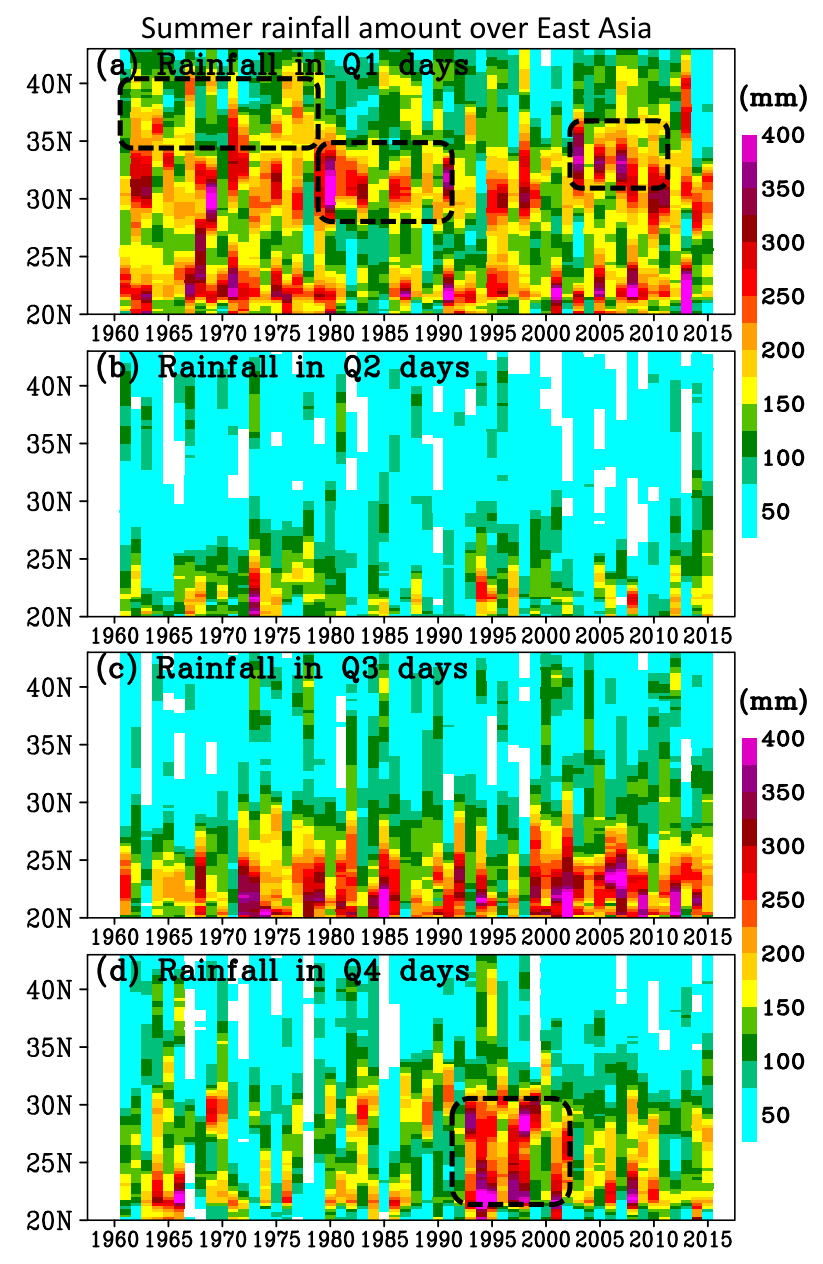

FIG. 6. Long-term variations of summer rainfall amount averaged in $108^{\circ}-125^{\circ} \mathrm{E}$ under Q1-Q4. The dashed rectangles denote the decadal periods with positive anomalies of rainfall derived in Fig. $2 \mathrm{~b}$.

(Fig. 7a) and $\sim 60 \%$ of the interannual variance at $30^{\circ}-35^{\circ} \mathrm{N}$ (Fig. 7b). It also explains a large fraction $(40 \%-50 \%)$ of the summer rainfall and its interannual variance at $35^{\circ}-41^{\circ} \mathrm{N}$.

Figure $6 \mathrm{~d}$ shows that the rainfall under Q4 condition mainly appears south of $31^{\circ} \mathrm{N}$ in the past 60 years. The Q4-related rainfall over SEC is small from the 1960s to 1980s and it becomes most pronounced during 1993-2002 with a maximum in 1998. Such an interdecadal trend coincides with the increasing occurrences of severe flooding over SEC since the mid-1990s (e.g., Kajikawa and Wang 2012; Choi et al. 2017). Overall, the rainfall amount related to Q4 occurrence ( $\sim 20 \%$ summer days) contributes $\sim 30 \%$ of the summer total rainfall at $27^{\circ}-$ $31^{\circ} \mathrm{N}$ (Fig. 7a). More strikingly, it explains a large fraction $(50 \%-60 \%)$ of the interannual variance of summer rainfall over there (Fig. 7b). Therefore, the strong monsoon southerlies coupling with a small diurnal cycle are related to the atmospheric conditions that produce a southward-displaced rainband and determine the variability of summer rainfall over SEC. Previous studies have shown that the monsoon southerlies at daily or longer time scales play a key role in regulating 

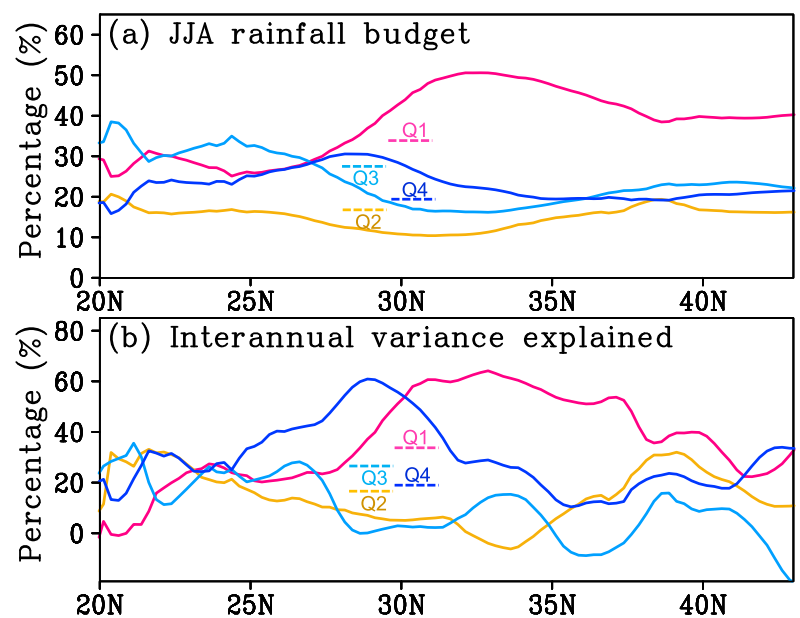

FIG. 7. Fraction ratio of (a) JJA rainfall amount and (b) its interannual variance contributed by the four quadrants of EASM diurnal cycle. The dashed lines denote the occurrence frequency of Q1-Q4.

the summer rainfall over East Asia (e.g., Ding and Chan 2005). Our study further highlights that the strong southerlies with different diurnal amplitudes (Q1 vs Q4) have a remarkably different influence on the spatial distributions and long-term variabilities of summer rainfall over China.

As a comparison, the rainfall under weak southerlies (Q2 and Q3) is mainly located south of $25^{\circ} \mathrm{N}$ (Figs. 6b,c). In particular, the Q3 group (weak monsoons with a small diurnal cycle), which resembles the synoptic patterns with tropical cyclones (Fig. 5c), tends to produce rainfall with evident interannual variation at the SEC coasts (Figs. 6c and 7). The Q2 group (weak monsoons but with a large diurnal cycle) has the lowest occurrence, and it produces the smallest fraction of summer rainfall (Figs. 6b and 7a). Nevertheless, the Q2 group explains the second largest interannual variance of rainfall at $36^{\circ}-41^{\circ} \mathrm{N}$ (Fig. $7 \mathrm{~b}$ ). It suggests that, even under weak monsoons, the enhanced diurnal variation of low-level winds in SEC is still related to the rainfall in northern China.

We further examine how much the DMV groups contribute to the spatial patterns of rainfall at interannual and interdecadal time scales. Figure 8 shows the rainfall patterns regressed onto the interannual and interdecadal series of Q1 and Q4 days in Fig. 4b. Given an interdecadal increase of Q1 days, the rainfall is a positive anomaly in northern China and the Indochina Peninsula, while it shows a negative anomaly in central China, northeast China, the southern area of the Korean Peninsula, and southwest Japan (Fig. 8a). The magnitude of rainfall anomaly is $10 \mathrm{~mm} \mathrm{day}^{-1}$ or more, which exceeds the climate-mean daily rainfall in the most areas. This rainfall pattern mainly occurs from the 1960 s to 1970 s when the decadal Q1 occurrence is above normal. The pattern is shifted to an opposite phase from the 1980s to 1990 s when the decadal Q1 occurrence is below normal. Figure 8b shows that the interdecadal series of Q4 days is associated with an enhanced rainfall in SEC and a suppressed rainfall in northern China. The increased occurrence of the monsoon southerlies with a small diurnal cycle from the 1980 s to 1990 s thus leads to the southward displacement of rainfall. The rainfall pattern over East Asia under Q4 is analogous to that under Q1 but with an opposite sign (Figs. 8a,b). The interdecadal change of rainfall induced by the decreased Q1 and increased Q4 in the twentieth century is highly consistent with the well-known rainfall pattern over China shifting from a "north flooding and south drought" mode to a "south flooding and north drought" mode (e.g., Wang 2001; Ding et al. 2008, 2018; Zhang 2015).

At an interannual time scale, the Q1 condition features a positive (negative) anomaly of rainfall north (south) of $30^{\circ} \mathrm{N}$ (see Fig. 8c). It suggests that the strong nocturnal speed-up of monsoon southerlies over SEC is conducive to rainfall in the adjacent northern areas (northern China, the Korean Peninsula, and Japan). The large diurnal amplitude of southerlies usually forms under a relatively warm condition with suppressed rainfall over SEC and Indochina Peninsula (Chen 2020). Figure 8d shows that the interannual Q4 occurrence tends to produce strong rainfall in central China near $30^{\circ} \mathrm{N}$. The positive rainfall anomaly under Q4 is also widespread in SEC and the Indochina Peninsula, in contrast to the negative anomaly over there under Q1 (cf. Figs. 8c,d). Overall, the differences between Q1 and Q4 in Figs. 8a-d suggest that the long-term variations of monsoon southerlies with different diurnal cycles play a key role in regulating the regional patterns of rainfall anomalies over East Asia. Scatterplots in Figs. 8e and $8 \mathrm{f}$ further confirm that the years with active Q1 occurrence are mainly related to the summer rainband displaced to northern China (generally regarded as strong monsoon years), while those years with active Q4 correspond with the rainband being displaced to central China.

\section{Atmospheric water vapor transports associated with the EASM diurnal cycle}

\section{a. Long-term variations of water vapor transports under four DMV conditions}

It is well recognized that the monsoon flow plays an essential role in the northward transports of water vapor in the EASM regions. Previous studies have investigated the atmospheric water vapor transports associated with the typical patterns of anomalous summer rainfall in China (e.g., Zhou and Yu 2005; Zhu et al. 2011; Sun and Wang 2015; Hu et al. 2019). In this section, we further examine the detailed patterns of water vapor transports and their long-term variability due to the different modes of EASM diurnal cycles, so that the formation of anomalous rainfall patterns can be further clarified.

Figure 9 shows the spatial patterns of water vapor fluxes and their convergence in summer. Climatologically, the water vapor fluxes in the tropical regions feature monsoon southwesterlies, with convergence at windward coasts/mountains (Fig. 9a). The moisture fluxes turn northward over East Asia at the west flank of the western Pacific subtropical high and induce moisture convergence at midlatitudes. In the days of strong monsoon southerlies (Q1 and Q4), water vapor fluxes are strengthened 
(a) Q1, interdecadal

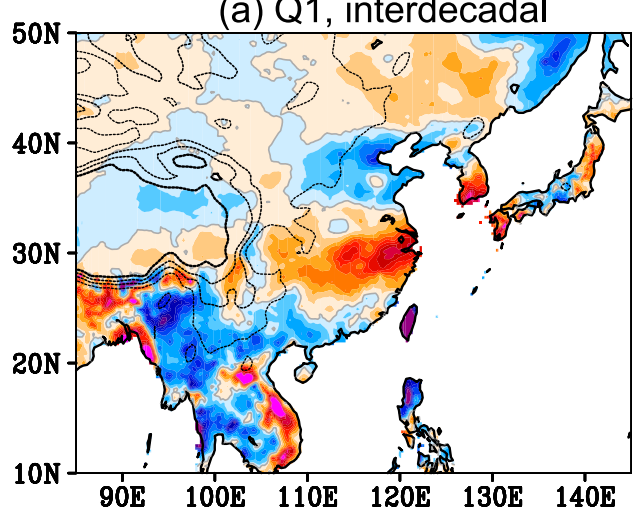

(c) Q1, interannual
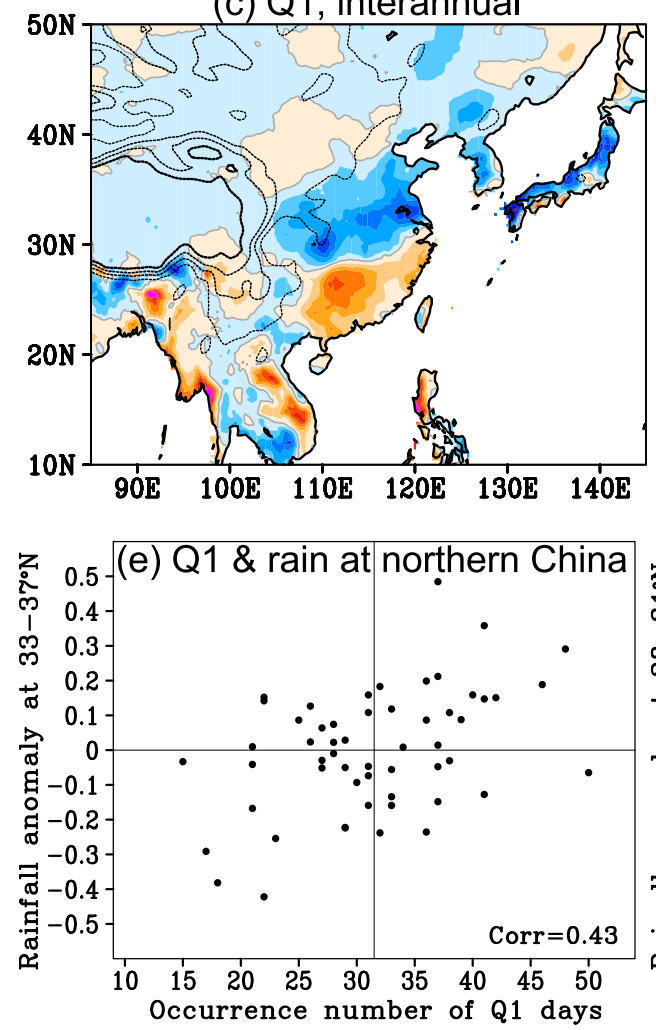

(b) Q4, interdecadal

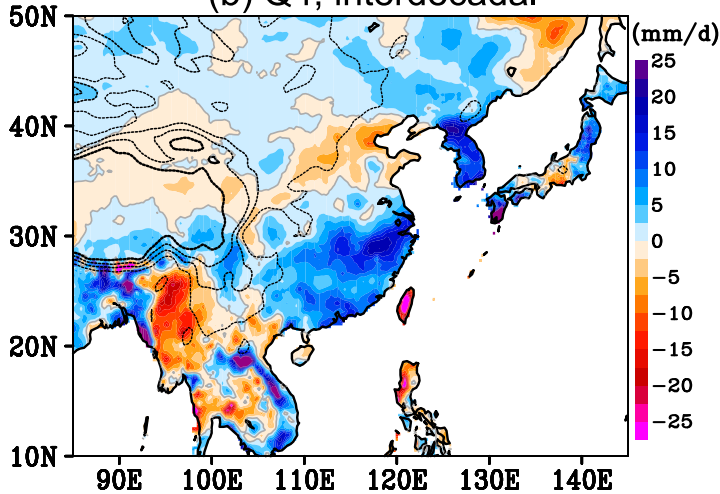

(d) Q4, interannual
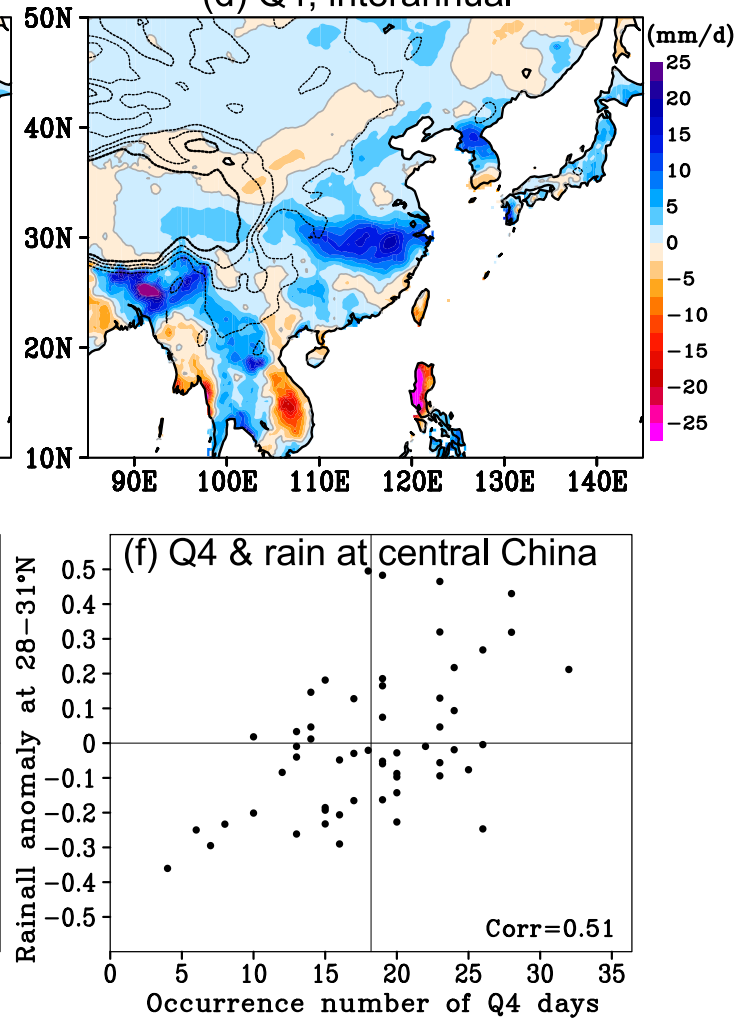

FIG. 8. Rainfall patterns regressed to the (a),(b) interdecadal and (c),(d) interannual variations of the occurrence days of Q1 and Q4 shown in Fig. 4b. (e) Scatterplot for the Q1 days and the normalized JJA rainfall anomaly at northern China from 1961 to 2015. (f) As in (e), but for the Q4 days and the rainfall anomaly at central China.

significantly over East Asia, at a magnitude about 3 times that of the JJA-mean fluxes (Figs. 9b,d). The strongest northward fluxes of more than $200 \mathrm{~kg} \mathrm{~m}^{-1} \mathrm{~s}^{-1}$ are established at SEC, where is the main entrance of water vapor to the EASM regions. What is surprising is the regional difference over China between the Q1 and Q4 groups. Under Q1, water vapor fluxes are maximized in central China and East China Sea (i.e., to the adjacent area north of SEC) (Fig. 9b). Moisture flux convergence is most evident in northern China plains at $30^{\circ}-40^{\circ} \mathrm{N}$. As a comparison, the maximum water vapor fluxes under Q4 are well established over SEC
(Fig. 9d). Accordingly, moisture flux convergence is displaced southward to SEC, with the local maxima at the coastal areas $\left(\sim 23^{\circ} \mathrm{N}\right)$ and the northern boundary of SEC $\left(\sim 29^{\circ} \mathrm{N}\right)$. Moisture flux convergence is relatively weak in the northern China plains under Q4, in a robust contrast to that under Q1. In the days of weak southerlies over SEC, the water vapor transport/ convergence is mainly confined to the tropical oceans, while it is suppressed at the midlatitudes of East Asia (Fig. 9c). These differences among the DMV groups in Fig. 9 correspond well to those of the rainfall patterns in Fig. 5. 
(a) JJA, daily mean

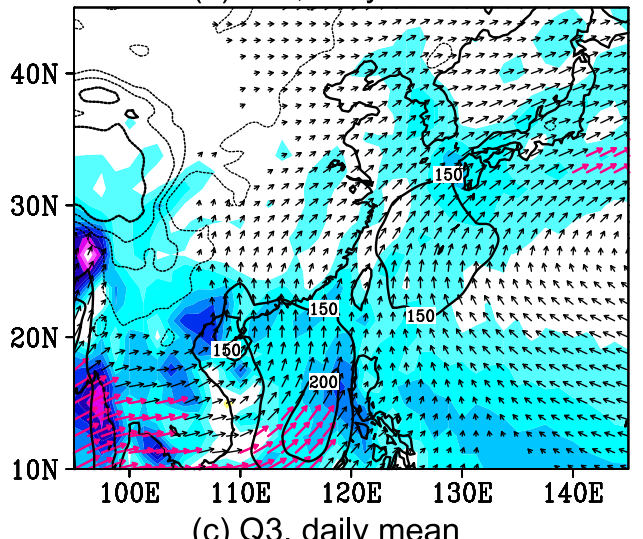

(c) 2 , daily mean

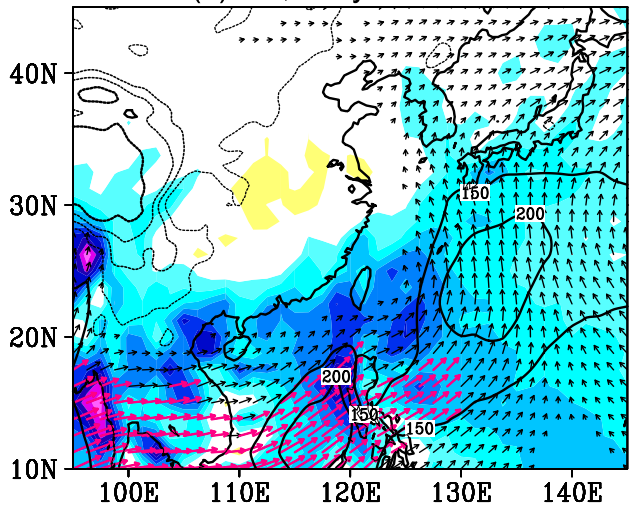

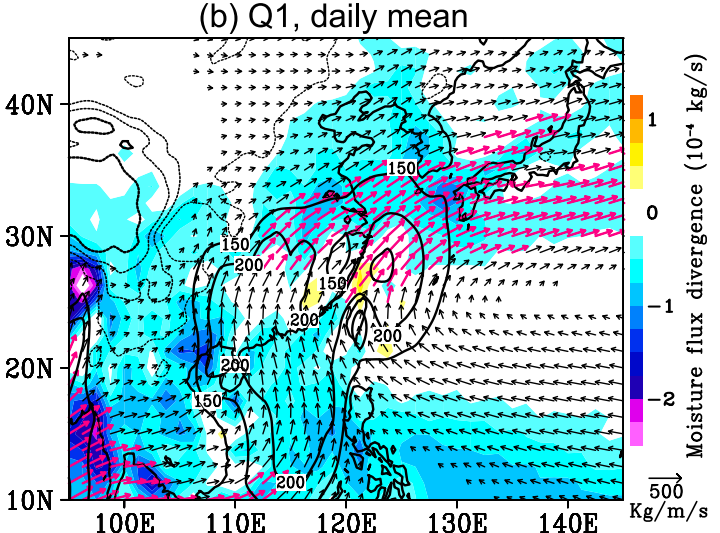

(d) Q4, daily mean

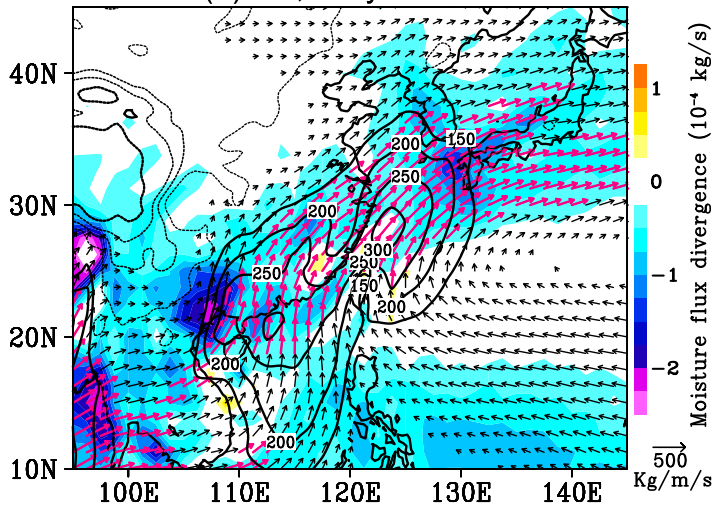

FIG. 9. Spatial patterns of daily mean water vapor transports (vectors) and convergence (shaded) averaged in (a) JJA and (b) Q1, (c) Q3, and (d) Q4. The red vectors denote the water vapor fluxes exceeding $250 \mathrm{~kg} \mathrm{~m}^{-1} \mathrm{~s}^{-1}$. The bold contours denote the northward water vapor flux exceeding $150 \mathrm{~kg} \mathrm{~m}^{-1} \mathrm{~s}^{-1}$. The black dashed lines denote the elevation at an interval of $1000 \mathrm{~m}$.

Figures 10 and 11 show the long-term variations of the northward moisture fluxes and the fraction by the DMV groups. The JJA-mean northward fluxes are large over SEC and South China Sea, and they are relatively small in the northern areas (Fig. 10a). The northward fluxes exhibit large interannual and interdecadal variations. The fluxes north of $30^{\circ} \mathrm{N}$ are relatively strong from the 1960 s to 1970 s and weak in 1980s, whereas they revive during 1994-96 and 2003-13. The northward fluxes south of $30^{\circ} \mathrm{N}$ are strong in the $1960 \mathrm{~s}$, the 1990s, and during 2003-13. The long-term change of water vapor fluxes is closely related to that of the southerly intensity (Figs. 2c and 3). Figure 10b shows that the water vapor fluxes due to Q1 undergo variations highly similar to the total value, with a correlation coefficient of about 0.68 at $27^{\circ}-35^{\circ} \mathrm{N}$. The Q1-related fluxes contribute to the largest proportion (up to $60 \%$ ) of total northward fluxes (Fig. 11a) and interannual variance (Fig. 11b). Figure 10d shows that the water vapor fluxes due to Q4 mainly contribute to the transports in the southern regions, and they become most pronounced in the 1990s. The Q4-related fluxes explain the second largest proportion of northward fluxes and interannual variance (Fig. 11). We also note that the Q4-related moisture fluxes and their meridional gradient are usually located south compared to the Q1-related ones (Figs. 10b,d). Overall, the monsoon southerlies with a small diurnal cycle (Q4) mainly deliver moisture to SEC, while those with a large diurnal cycle (Q1) can extend farther to the northern China plains. Such differences in the long-term variations of moisture fluxes between Q1 and Q4 groups correspond well to those of rainfall (Figs. 10a,d and $6 a, d)$. It suggests that the monsoon southerlies with different diurnal cycles play a vital role in modulating the interannual and interdecadal variations of water vapor fluxes, thereby regulating the summer rainfall over East Asia. Water vapor transports on land are much smaller under weak southerlies (Figs. 10c and 11a), although the Q3-related moisture fluxes may explain some variance at the coasts of SEC near $24^{\circ} \mathrm{N}$ (Fig. 11b).

To further clarify the influence of EASM diurnal cycles, we estimate the patterns of water vapor fluxes/convergence regressed onto the interdecadal and interannual series of the DMV occurrence days shown in Fig. 4b. Figure 12a shows that, according to the interdecadal variation of Q1 days, the water vapor fluxes exhibit an anticyclonic pattern in the East China Sea with convergence in northern China. It suggests that an enhanced subtropical high helps to produce more rainfall in 


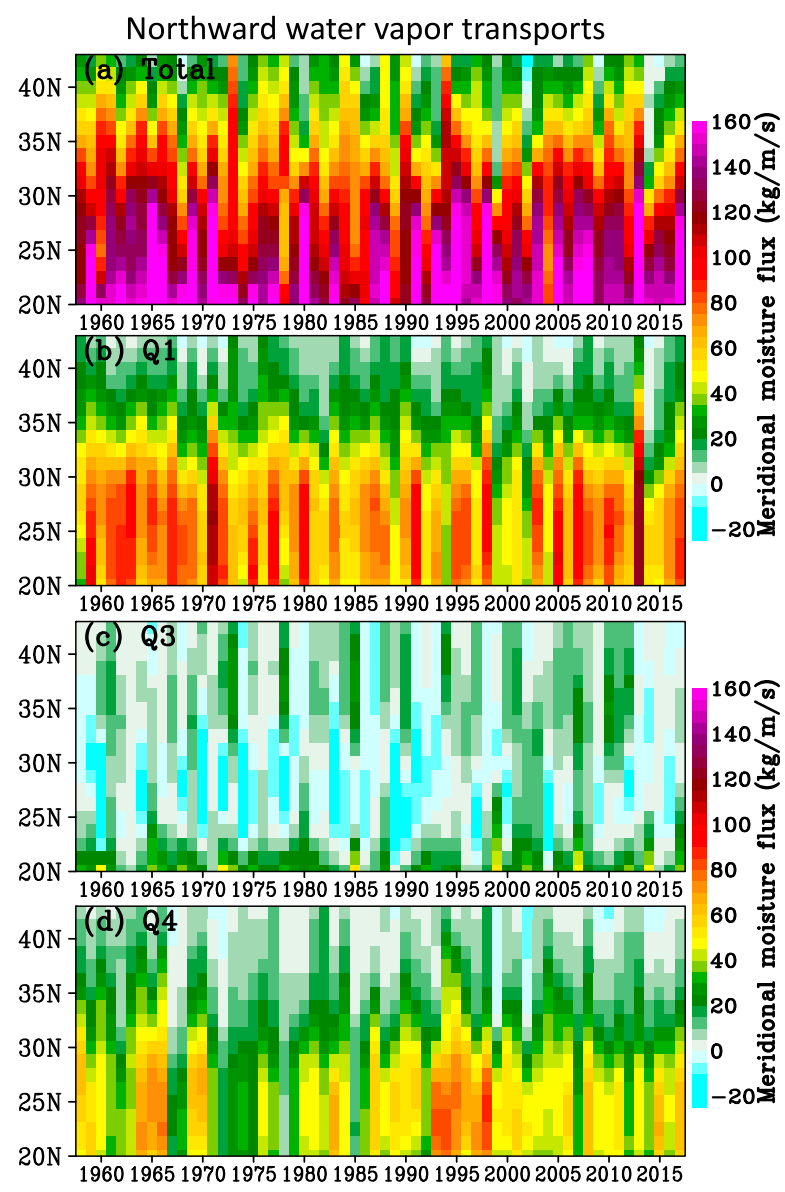

FIG. 10. Long-term variations of northward water vapor transports averaged in $108^{\circ}-125^{\circ} \mathrm{E}$ (a) for the JJA mean and for the fractions under (b) Q1, (c) Q3, and (d) Q4.

northern China by increasing the northward moisture fluxes. Another anticyclonic pattern of water vapor fluxes occurs in the Philippine Sea, with flux convergence in the northern SCS. Moisture convergence is suppressed over SEC instead. Figure $12 \mathrm{~b}$ shows that, according to the interdecadal variation of Q4 days, the anticyclonic pattern of water vapor fluxes is established in the northwestern Pacific and northern SCS. Moisture flux convergence occurs in SEC, the East China Sea, and western Japan. In general, the anomalies of moisture convergence (divergence) are closely related to the enhanced (suppressed) southwesterly fluxes at the northern (southern) flank of the anticyclonic pattern. The spatial patterns of moisture flux convergence in Figs. 12a and 12b are well collocated with the rainfall anomalies over China in Figs. 8a and 8b. With the decrease (increase) of Q1 (Q4) occurrence days in the twentieth century, we expect a southward displacement of moisture flux convergence from northern China to SEC. Such a long-term trend of EASM diurnal cycles corresponds to the interdecadal change of rainfall anomalies in Fig. $2 b$. Overall, the water vapor fluxes and convergence by monsoon southerlies at interdecadal time scale produce the
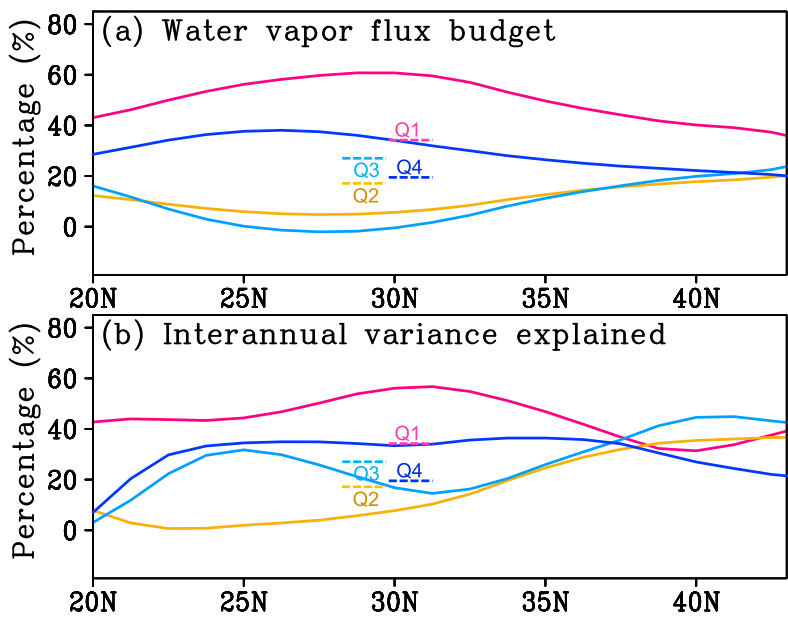

FIG. 11. Fraction ratio of (a) northward water vapor transports and (b) its interannual variance contributed by the four quadrants of EASM diurnal cycle. The dashed lines denote the occurrence frequency of Q1-Q4.

south-north dipole patterns of rainfall anomalies in China, which is similar to the second mode in Zhou and Yu (2005). The results of the present study further highlight that the moisture convergence in the northern (southern) areas of China is strongly regulated by the monsoon southerlies with a large (small) diurnal cycle.

At the interannual time scale, the Q1 occurrence days are closely associated with an anticyclonic pattern of water vapor fluxes in the SCS and western Pacific (Fig. 12c). Moisture flux divergence is dominant over there and extends to SEC, while the anomaly of flux convergence is pronounced at the north edge of the anticyclonic pattern. It helps to produce rainfall at the areas at $30^{\circ}-40^{\circ} \mathrm{N}$ (northern China, the Korean Peninsula, and Japan). Figure $12 \mathrm{~d}$ shows that the interannual variation of Q4 occurrence days also features an anticyclonic pattern of water vapor fluxes in the SCS and western Pacific. The anticyclonic pattern under Q4, however, is oriented in a west-east direction rather than a meridional extension under Q1 (cf. Figs. 12c,d). Moisture flux divergence is mainly confined to a zonal band at $15^{\circ}-22^{\circ} \mathrm{N}$ (the Philippine Sea and northern SCS), while flux convergence is well established at SEC, farther south than that under Q1. The pattern is analogous to the well-known anomalous anticyclone over the western Pacific related to EASM at the interannual time scale (Wu et al. 2009; Song and Zhou 2014a,b). Moisture convergence also occurs over Bangladesh and the southeast peripheries of Tibetan Plateau, where westerly water vapor fluxes are prevalent. It is thought that the eastwardmoving rainfall systems and increased cloudiness from these upstream areas to SEC may reduce daytime heating and thereby diurnal wind cycle in Q4 (Chen 2020).

Overall, the regression patterns of water vapor transports onto the strong monsoon southerlies (both Q1 and Q4) suggest that the anticyclonic anomalies from the SCS and western Pacific play a crucial role in regulating the interannual variations of moisture budget in the EASM regions (Figs. 12c,d). They seem to be closely associated with the various westward 
(a) Q1, interdecadal

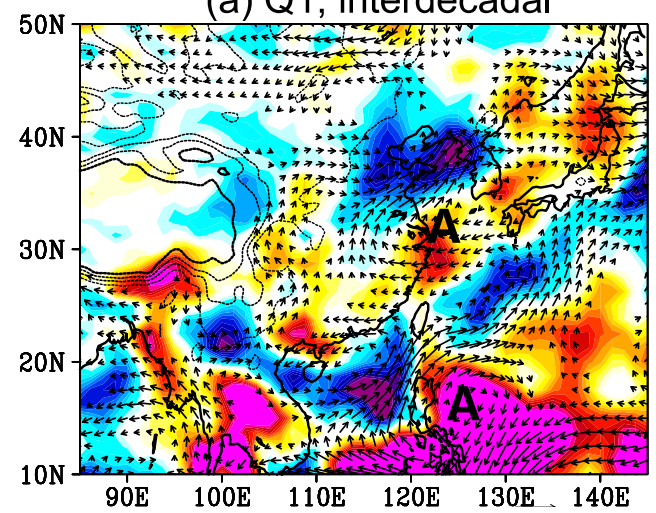

(c) Q1, interannual

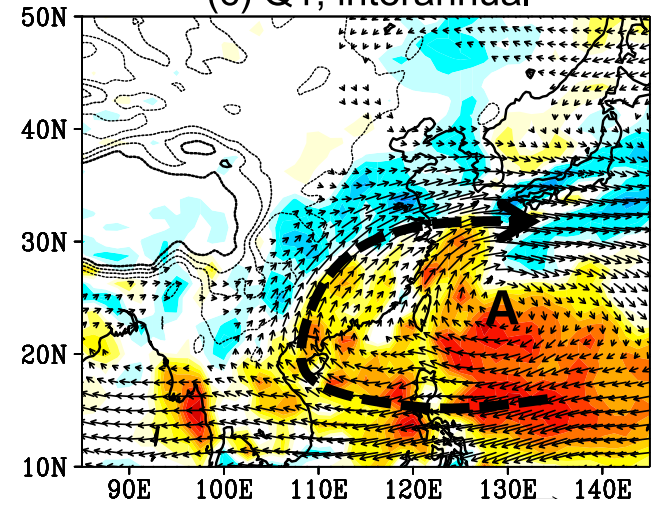

(b) Q4, interdecadal

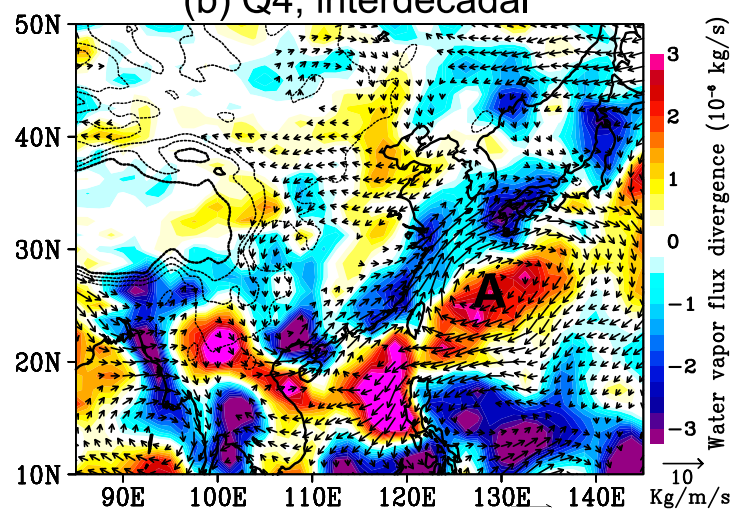

(d) Q4, interannual

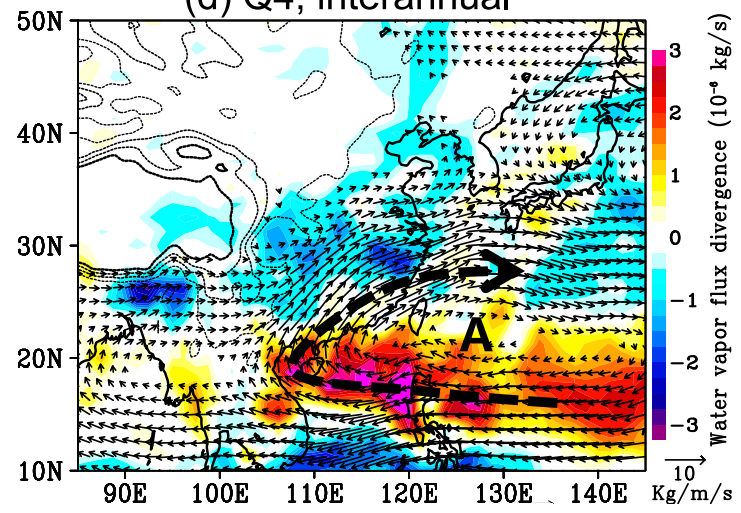

FIG. 12. Spatial patterns of water vapor transports and convergence regressed to the interdecadal and interannual variations of the occurrence days of Q1 and Q4 shown in Fig. 4b. The anomalous anticyclone is marked by "A" and the dashed lines.

expansions of the western Pacific subtropical high. Similar patterns of water vapor fluxes are also shown to explain the first mode of rainfall anomalies, which exhibits large interannual variations over China (e.g., Zhou and Yu 2005; Hu et al. 2019). In this study, by taking the diurnal component into account, we further divide the strong monsoon southerlies into two different modes that explain well the detailed locations of moisture convergence in a good relation to the rainfall anomalies between southern and northern China. The differences of moisture transport/convergence between Q1 and Q4 also suggest that the large diurnal cycle when coupled with monsoon southerlies over SEC acts as an extra regional force pushing the summer rainband northward.

\section{b. Impacts on the diurnally varying moisture transports}

Figure 13 shows the diurnally varying water vapor fluxes and convergence associated with the EASM diurnal cycles. Under Q1, the southerly fluxes over SEC are estimated as $\sim 200 \mathrm{~kg} \mathrm{~m}^{-1} \mathrm{~s}^{-1}$ in the afternoon (Fig. 13a) and increase to $\sim 250 \mathrm{~kg} \mathrm{~m}^{-1} \mathrm{~s}^{-1}$ in the morning (Fig. 13b). Two local maxima are seen over the East China Sea and the eastern periphery of the Yun-gui Plateau, where nocturnal low-level jets prefer to occur (Du et al. 2014; Du and Chen 2019). Accordingly, the moisture flux convergence is greatly enhanced in the morning at $30^{\circ}-40^{\circ} \mathrm{N}$ in the northern China plains and at the western coasts of the Korean Peninsula and Japan (Fig. 13b). The ageostrophic wind component in monsoon southerlies is thought to enhance the net moisture fluxes in the morning (Chen et al. 2009; G. Chen et al. 2017; Xue et al. 2018), thereby leading to a remarkable increase of morning rainfall (Shin et al. 2019; Chen 2020). Monsoon southerlies thus act to inject more energy into the East Asian rainband after midnight through transportation of water vapor from low latitudes. In contrast, under Q4, water vapor fluxes over SEC are less changed from afternoon to morning because of a small diurnal cycle of monsoon southerlies (Figs. 13c,d). The convergence of water vapor flux on land of SEC (at $\sim 28^{\circ} \mathrm{N}$ ) is even marginally large in the afternoon. The diurnal range of flux convergence is also small at the western coasts of the Korean Peninsula and Japan. These differences between Q1 and Q4 thus suggest that the strong monsoon southerlies with different diurnal cycles play an important role in regulating the regional moisture budget at subdaily time scale.

We further examine the long-term variations of moisture flux convergence. Figure 14a show that moisture flux convergence in the morning has pronounced long-term variations at $30^{\circ}-40^{\circ} \mathrm{N}$. Strong convergence is seen at $35^{\circ}-40^{\circ} \mathrm{N}$ from the 1960 s to $1970 \mathrm{~s}$ and is displaced south to $30^{\circ}-35^{\circ} \mathrm{N}$ in the $1980 \mathrm{~s}$. It is farther 
(a) Q1, afternoon hours

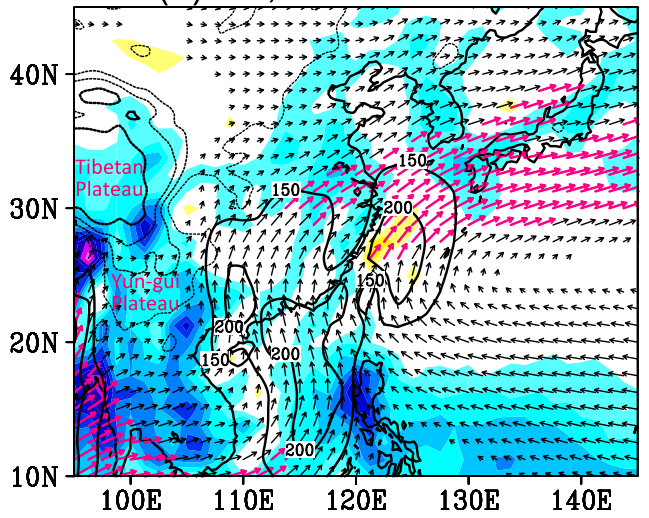

(c) Q4, afternoon hours

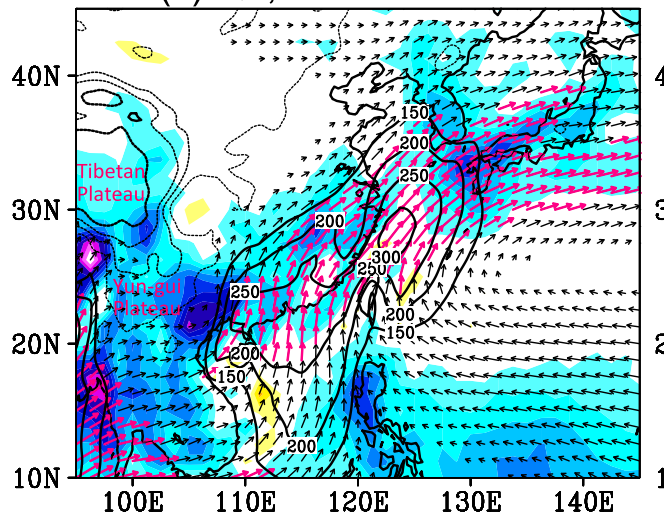

(b) Q1, morning hours

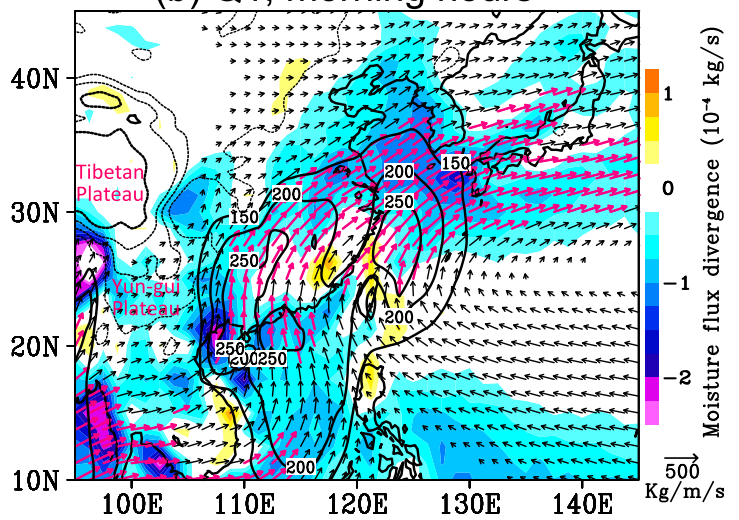

(d) Q4, morning hours

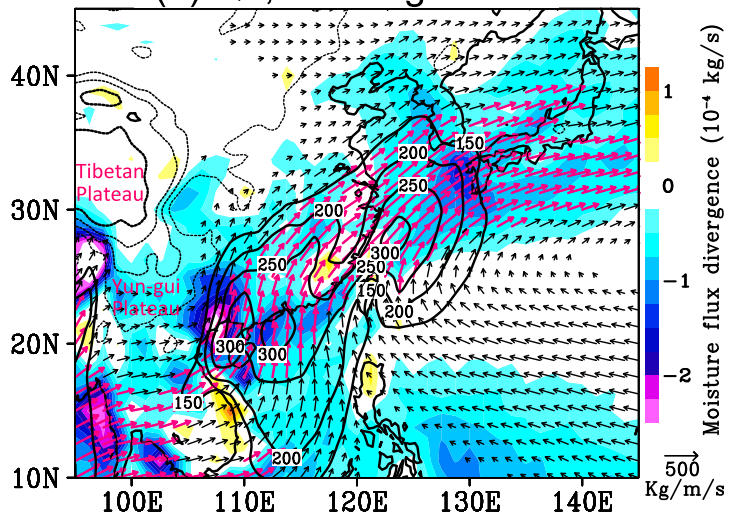

FIG. 13. Spatial patterns of water vapor transports (vectors) and convergence (shaded) under Q1 and Q4 in (a),(c) afternoon and (b),(d) morning hours. The red vectors denote the water vapor fluxes exceeding $250 \mathrm{~kg} \mathrm{~m}^{-1} \mathrm{~s}^{-1}$. The bold contours denote the northward water vapor flux exceeding $150 \mathrm{~kg} \mathrm{~m}^{-1} \mathrm{~s}^{-1}$. The black dashed lines denote the elevation at an interval of $1000 \mathrm{~m}$.

shifted to the south of $30^{\circ} \mathrm{N}$ in the $1990 \mathrm{~s}$; it is also strong at $37^{\circ}-40^{\circ} \mathrm{N}$ in some years. Strong convergence returns to the latitudes near $35^{\circ} \mathrm{N}$ in $2003-13$. Such interdecadal changes of moisture convergence in the morning are highly consistent with those of rainfall anomalies (cf. Figs. 14a and 2b). In contrast, the variations of moisture convergence in the afternoon have a much smaller amplitude (not shown). Therefore, the water vapor transports and convergence in the morning are mainly responsible for the long-term variations of EASM rainfall.

Figure 14b shows that a large portion of morning-hour moisture convergence can be attributed to the Q1 condition. In particular, there is a high similarity in Figs. 14a and 14b for the interannual/interdecadal variations north of $30^{\circ} \mathrm{N}$. Strong monsoon southerlies with a large diurnal cycle are thus crucial for regulating the long-term variabilities of moisture convergence over East Asia. In contrast, the Q4-related moisture convergence in the morning (also in the afternoon) is somewhat strong in the mid-1990s south of $30^{\circ} \mathrm{N}$ (Fig. 14d), but it has no obvious variations north of $30^{\circ} \mathrm{N}$. As for the weak southerlies under Q3, the variations of moisture convergence mainly occur at coasts south of $25^{\circ} \mathrm{N}$. Previous studies noted that the morning proportion of rainfall undergoes a long-term increase (decrease) in the southern (northern) areas of China in the twentieth century (Yuan et al. 2013; Chen et al. 2014). In the present study, we can attribute such a long-term trend of rainfall to an increase of Q4 and a decrease of Q1. Meanwhile, a recent recovery of Q1 occurrence in 2003-13 seems to result in a moderate increase of rainfall in northern China (Ding et al. 2009; Zhu et al. 2011). Overall, the strong monsoon southerlies with a large diurnal cycle play a key role in regulating the water vapor transports and convergence in a close association with the long-term change of summer rainfall.

\section{Conclusions and discussion}

The seasonal and interannual/interdecadal variations of EASM system has received much attention. This paper revisits these long-term variabilities by linking them to the diurnal cycles of monsoon southerlies that denote key regional forcings. We decompose monsoon southerlies into four different dynamic groups by taking both daily and diurnal components into account. We examine the long-term variations of the four DMV groups and clarify their impacts on rainfall variations 
Water vapor flux divergence in the morning
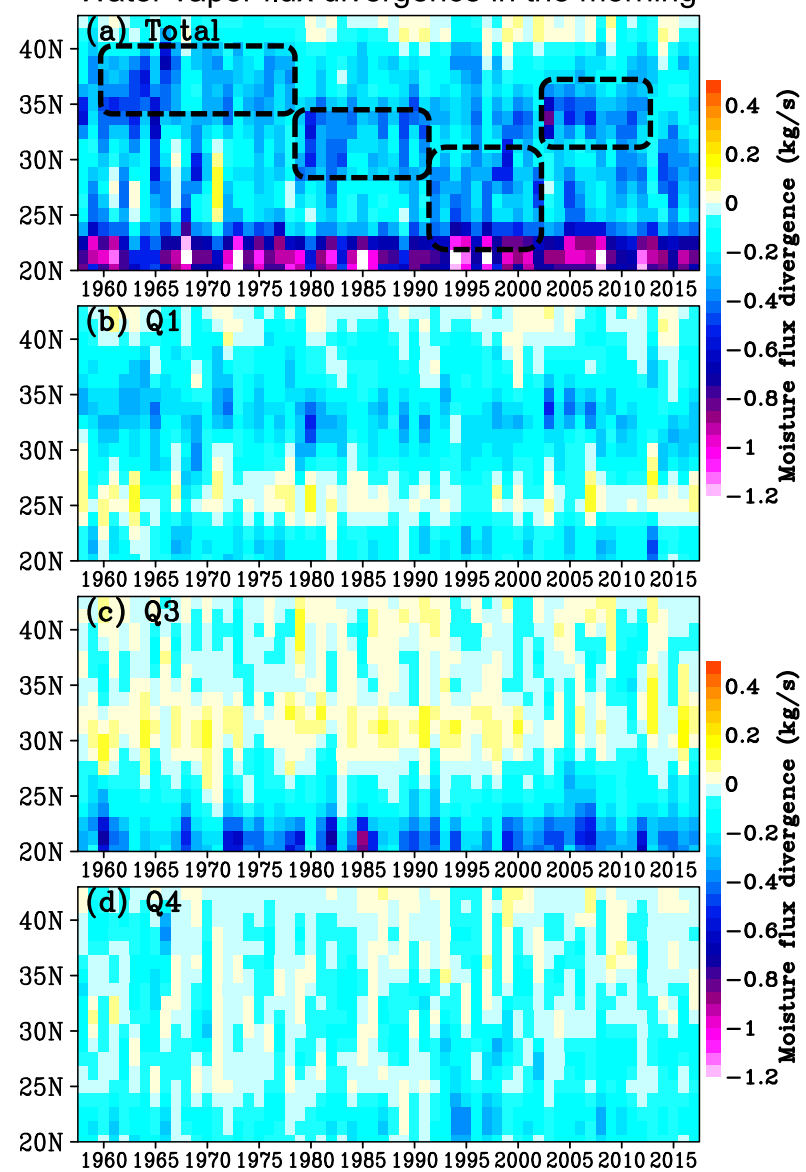

FIG. 14. Long-term variations of water vapor flux divergence in morning hours averaged in $108^{\circ}-125^{\circ} \mathrm{E}$ (a) for the JJA mean and for the fractions under (b) Q1, (c) Q3, and (d) Q4. The dashed rectangles in (a) denote the decadal periods with positive anomalies of rainfall derived in Fig. $2 b$.

and water vapor transports. The major findings are summarized as below.

1) Diurnal variations of low-level southerlies with a nocturnal maximum become pronounced in summer. The number of occurrences of days of strong monsoon southerlies with a large diurnal cycle (Q1) increases notably from June to July, in relation to the northward march of EASM. The Q1 occurrence averaged in JJA is about 35 days from the 1960s to 1970 s, whereas it decreases to a minimum of about 26 days from the 1980s to 1990s. The interdecadal shift occurs in the early 1980s. As a comparison, the occurrence of strong monsoon southerlies with a small diurnal cycle (Q4) is as low as $~ 14$ days in the 1970 s and increases to $\sim 24$ days in the 1990s. This interdecadal decrease (increase) of Q1 (Q4) occurrence days corresponds well to the long-term weakening of the EASM in the twentieth century. The Q1 and Q4 occurrences turn back to normal in 2003-12, indicating a moderate recovery of the EASM intensity. These long-term variations of diurnal cycles in monsoon southerlies can be regarded as a key feature of the EASM system.

2) Strong monsoon southerlies help to increase the rainfall in the subtropical areas of East Asia. However, the spatial patterns of induced rainfall anomalies over China are shown to be remarkably different under Q1 and Q4 given different diurnal amplitudes in the strong monsoons. In Q1 days, the southerlies with a large diurnal cycle produce anomalously strong rainfall in northern China (north of $30^{\circ} \mathrm{N}$ ). In Q4 days, however, the monsoon rainfall is mostly confined at SEC (south of $\left.30^{\circ} \mathrm{N}\right)$. The Q1 (Q4)-related rainfall can account for $\sim 60 \%$ of the interannual variance of summer rainfall in the north (south) areas of China. The interdecadal decrease (increase) of Q1 (Q4) in the last 40 years of the twentieth century is associated with the shift of rainfall anomalies from the "north flooding and south drought" mode to the "north drought and south flooding" mode. The increasing Q1 occurrence in the recent years turns to enhance rainfall in northern China.

3) The strong monsoon southerlies over East Asia are generally associated with the large-scale anticyclonic patterns of water vapor transport anomalies over the western Pacific. Under Q4, the northward water vapor transports and convergence mainly tend to maximize at SEC. Under Q1, however, the maximum of water vapor transports (convergence) is mainly established at central (northern) China, while the moisture flux divergence is more extensive over the western Pacific, SCS, and southern China. These differences between Q1 and Q4 are closely related to the different expansion patterns of the western Pacific subtropical high. Under Q1, the northward transports of water vapor over SEC increase by $\sim 20 \%$ in the morning compared to those in the afternoon. The induced convergence can contribute to a major proportion of the interannual variations of moisture convergence in northern China, thereby linking to the interannual variations of summer rainfall over there. The interdecadal variations of morninghour moisture convergence (largely due to Q1) also correspond well to those of rainfall anomalies. The monsoon southerlies with a large diurnal cycles thus play a key role in regulating the regional water budget at both subdaily and longer time scales.

Previous studies have connected the long-term variabilities of EASM rainfall to the thermal forcings such as the snow cover over the Asian continent and SSTA in the tropical oceans (e.g., Chang et al. 2000; Gong and Ho 2002; Ding et al. 2009; Duan et al. 2013). However, it is still unclear why the diurnal cycles of summer monsoon exhibit long-term variations. A possible cause is the land heating over the Asian continent and its contrast to adjacent oceans (Song et al. 2014; Huang and Chen 2015; Huang et al. 2019). As shown in Fig. 15a, the long-term variations of Q1 occurrence are positively (negatively) related to the low-level temperature on East Asian land (the adjacent ocean). Similar patterns but at opposite phases are seen for the variations of Q4 occurrence (see Fig. 15b). This suggests that the long-term 
(a) Corr. Q1 and 925-hPa Temperature

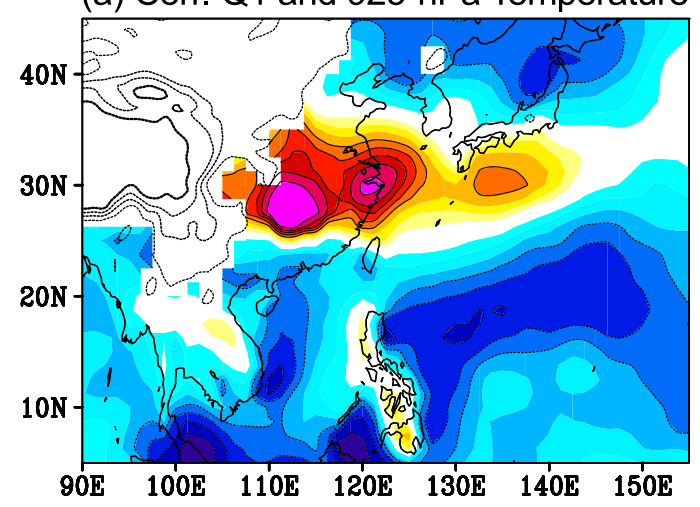

(c) Corr. Q1 and SST in JJA

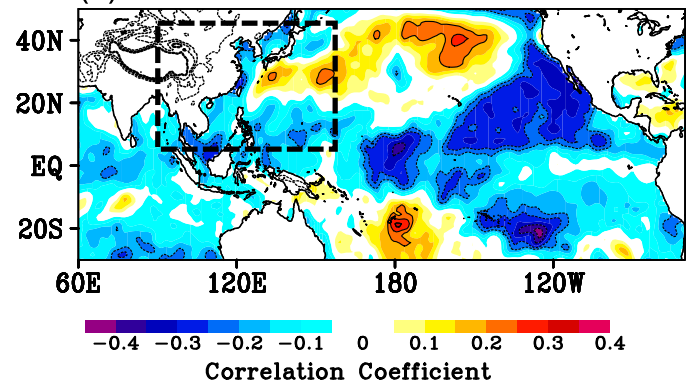

(b) Corr. Q4 and 925-hPa Temperature

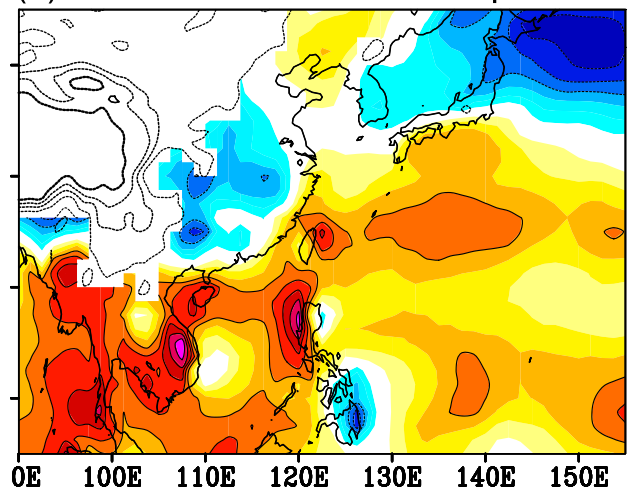

(d) Corr. Q4 and SST in JJA

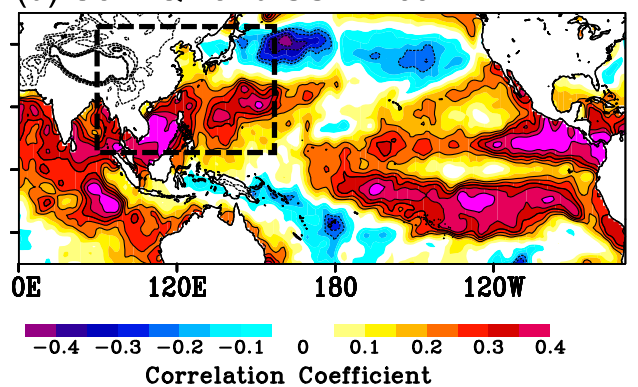

FIG. 15. Correlation between the DMV time series with (a),(b) JJA-mean temperature at $925 \mathrm{hPa}$ and (c),(d) SST. The DMV time series shown in Fig. $4 \mathrm{~b}$ are used. The dashed rectangles in (c) and (d) outline the targeted domains shown in (a) and (b). The contours show the correlation coefficients above 0.2 or below -0.2 that exceed the $90 \%$ confidence level. The dashed lines over Asia denote the elevation at an interval of $1000 \mathrm{~m}$.

variations of EASM diurnal cycle are closely associated with the land-sea thermal contrast, in which Q1 (Q4) is favored by the enhanced (suppressed) heated land relative to the adjacent ocean. These correlation patterns with air temperature (see Figs. 15a,b) correspond well to those with SST (see Figs. 15c,d), in which Q1 (Q4) has a negative (positive) correlation with SST near East Asia. As adjacent oceans undergo the warming observed in the last century, the reduced land-sea thermal contrast may explain, at least in part, the long-term decrease (increase) of Q1 (Q4) occurrence. Q1 and Q4 are also closely correlated with SST far in the Indian Ocean, equatorial central-eastern Pacific, and northern Pacific (see Figs. 15c,d). This implies a potential influence of ENSO and PDO on EASM, which deserves further study (Wu et al. 2009; Zhou et al. 2013; Song and Zhou 2014a,b). The changes in aerosols and land use due to anthropogenic activity are also thought to affect surface heat budget (e.g., Lau et al. 2006; Li et al. 2016). The aerosol-induced cooling over continental East Asia may reduce the land-sea thermal contrast and affect monsoon circulation (Song et al. 2014). We expect that the small diurnal cycle of low-level winds in recent decades (Figs. 2d and 3) may remain in the near future because of the suppressed mixing in daytime PBL under the relatively polluted air conditions. Therefore, estimating the change of monsoon rainfall in future climate requires climate models with a proper treatment of diurnal cycles relating to aerosol radiative effects and/or air-sea-land interaction.

Based on the evidence presented in this study, we reveal the subdaily variability of the EASM and its close relationship to the variabilities at longer time scales. Another issue deserving future work is the upscaling feedback effects of the diurnal cycles to the large-scale circulations. Early studies have noted that the daytime heating of high terrain such as the Tibetan Plateau helps to drive the upslope winds and afternoon deep convection, which plays a key role in establishing the monsoonal circulation over Asia (Yeh et al. 1979; Kuo and Qian 1981; Krishnamurti and Kishtawal 2000; Wu et al. 2012, 2015). Our study suggests that the diurnal cycle of monsoon southerlies with a midnight maximum of wind speed, as a delayed response to landmass heating (Blackadar 1957; Chen 2020), is another key feature of the EASM system. Enhanced monsoon southerlies at night may provide favorable conditions for the formation of moist organized convection and mesoscale convective vortices that may in turn modulate synoptic-scale atmospheric conditions during long-lasting heavy rainfall events (G. Chen et al. 2017; Zhang et al. 2018; Xue et al. 2018; Zeng et al. 2019). Further studies of the diurnal cycles under different large-scale circulations help to improve our understanding of the regional climate change and extreme weather. 
Acknowledgments. The authors express thanks to GSFC/ TSDIS of NASA for providing TRMM data, to Hirosaki University for providing APHRODITE data, and to JMA for providing JRA-55 data. They also thank three anonymous reviewers for helpful comments. This study is supported by the National Key Research and Development Program of China (Grant 2016YFA0600704) and the National Natural Science Foundation of China (Grants 41575068, 41530530, and 42075006).

\section{REFERENCES}

Blackadar, A. K., 1957: Boundary-layer wind maxima and their significance for the growth of nocturnal inversions. Bull. Amer. Meteor. Soc., 38, 283-290, https://doi.org/10.1175/15200477-38.5.283.

Chang, C. P., Y. Zhang, and T. Li, 2000: Interannual and interdecadal variations of the East Asian summer monsoon and tropical Pacific SSTs. Part I: Roles of the subtropical ridge. J. Climate, 13, 4310-4325, https://doi.org/10.1175/15200442(2000)013<4310:IAIVOT>2.0.CO;2.

Chen, G., 2020: Diurnal cycle of the Asian summer monsoon: Air pump of the second kind. J. Climate, 33, 1747-1775, https:// doi.org/10.1175/JCLI-D-19-0210.1.

— W. Wha, and T. Iwasaki, 2009: Diurnal variation of precipitation over southeastern China: 2. Impact of the diurnal monsoon variability. J. Geophys. Res., 114, D21105, https:// doi.org/10.1029/2009JD012181.

$\_, \ldots$, M. Sawada, and T. Iwasaki, 2013: Influence of summer monsoon diurnal cycle on moisture transport and precipitation over eastern China. J. Geophys. Res. Atmos., 118, 3163 3177, https://doi.org/10.1002/jgrd.50337.

—, T. Iwasaki, H. Qin, and W. Sha, 2014: Evaluation of the warm-season diurnal variability over East Asia in recent reanalyses JRA-55, ERA-Interim, NCEP CFSR, and NASA MERRA. J. Climate, 27, 5517-5537, https://doi.org/10.1175/ JCLI-D-14-00005.1.

—, W. Sha, T. Iwasaki, and Z. Wen, 2017: Diurnal cycle of a heavy rainfall corridor over East Asia. Mon. Wea. Rev., 145, 3365-3389, https://doi.org/10.1175/MWR-D-16-0423.1.

_- R. Lan, W. Zeng, H. Pan, and W. Li, 2018: Diurnal variations of rainfall in surface and satellite observations at the monsoon coast (South China). J. Climate, 31, 1703-1724, https://doi.org/ 10.1175/JCLI-D-17-0373.1.

Chen, H., R. Yu, J. Li, W. Yuan, and T. Zhou, 2010: Why nocturnal long-duration rainfall presents an eastward-delayed diurnal phase of rainfall down the Yangtze River valley. J. Climate, 23, 905-917, https://doi.org/10.1175/2009JCLI3187.1.

Chen, T.-C., S.-Y. Wang, W.-R. Huang, and M.-C. Yen, 2004: Variation of the East Asian summer monsoon rainfall. $J$. Climate, 17, 744-762, https://doi.org/10.1175/1520-0442(2004) $017<0744$ :VOTEAS $>2.0 . \mathrm{CO} ; 2$.

Chen, X., F. Zhang, and K. Zhao, 2017: Influence of monsoonal wind speed and moisture content on intensity and diurnal variations of the mei-yu season coastal rainfall over South China. J. Atmos. Sci., 74, 2835-2856, https://doi.org/10.1175/ JAS-D-17-0081.1.

Chen, Y., and P. Zhai, 2013: Persistent extreme precipitation events in China during 1951-2010. Climate Res., 57, 143-155, https://doi.org/10.3354/cr01171.

Choi, K.-S., H.-D. Kim, S.-D. Kang, and D.-W. Kim, 2017: Interdecadal change of South China Sea summer monsoon intensity in the mid-1990s. Int. J. Climatol., 37, 559-569, https:// doi.org/10.1002/joc.4615.
Ding, Y., and J. C. Chan, 2005: The East Asian summer monsoon: An overview. Meteor. Atmos. Phys., 89, 117-142, https:// doi.org/10.1007/s00703-005-0125-Z.

_ Z. Wang, and Y. Sun, 2008: Inter-decadal variation of the summer precipitation in East China and its association with decreasing Asian summer monsoon. Part I: Observed evidences. Int. J. Climatol., 28, 1139-1161, https://doi.org/10.1002/joc.1615.

_ , Y. Sun, Z. Wang, Y. Zhu, and Y. Song, 2009: Inter-decadal variation of the summer precipitation in China and its association with decreasing Asian summer monsoon. Part II: Possible causes. Int. J. Climatol., 29, 1926-1944, https://doi.org/10.1002/joc.1759.

—, D. Si, Y. Liu, Z. Wang, Y. Li, L. Zhao, and Y. Song, 2018: On the characteristics, driving forces and inter-decadal variability of the East Asian summer monsoon (in Chinese with English abstract). Chin. J. Atmos. Sci., 42, 533-558.

Du, Y., and G. Chen, 2019: Climatology of low-level jets and their impact on rainfall over southern China during early-summer rainy season. J. Climate, 32, 8813-8833, https://doi.org/10.1175/ JCLI-D-19-0306.1.

—, Q. H. Zhang, Y. L. Chen, Y. Y. Zhao, and X. Wang, 2014: Numerical simulations of spatial distributions and diurnal variations of low-level jets in China during early summer. J. Climate, 27, 5747-5767, https://doi.org/10.1175/JCLI-D-13-00571.1.

Duan, A., M. Wang, Y. Lei, and Y. Cui, 2013: Trends in summer rainfall over China associated with the Tibetan Plateau sensible heat source during 1980-2008. J. Climate, 26, 261-275, https://doi.org/10.1175/JCLI-D-11-00669.1.

Fujinami, H., T. Sato, H. Kanamori, and F. Murata, 2017: Contrasting features of monsoon precipitation around the Meghalaya Plateau under westerly and easterly regimes. J. Geophys. Res. Atmos., 122, 9591-9610, https://doi.org/10.1002/2016JD026116.

Geng, B., and H. Yamada, 2007: Diurnal variations of the Meiyu/ Baiu rain belt. SOLA, 3, 61-64, https://doi.org/10.2151/sola. 2007-016.

Gong, D., and C. Ho, 2002: Shift in the summer rainfall over the Yangtze River valley in the late 1970s. Geophys. Res. Lett., 29, 1436, https://doi.org/10.1029/2001GL014523.

Guan, P., G. Chen, W. Zeng, and Q. Liu, 2020: Corridors of mei-yuseason rainfall over eastern China. J. Climate, 33, 2603-2626, https://doi.org/10.1175/JCLI-D-19-0649.1.

Han, Z., and T. Zhou, 2012: Assessing the quality of APHRODITE high-resolution daily precipitation dataset over contiguous China (in Chinese with English abstract). Chin. J. Atmos. Sci., 36, 1006-9895.

Hersbach, H., and Coauthors, 2020: The ERA5 global reanalysis. Quart. J. Roy. Meteor. Soc., 146, 1999-2049, https://doi.org/ 10.1002/qj.3803.

Hu, Y., Y. Deng, Z. Zhou, C. Cui, and X. Dong, 2019: A statistical and dynamical characterization of large-scale circulation patterns associated with summer extreme precipitation over the middle reaches of Yangtze River. Climate Dyn., 52, 62136228, https://doi.org/10.1007/s00382-018-4501-z.

Huang, W.-R., and K. C. Chen, 2015: Trends in pre-summer frontal and diurnal rainfall activities during 1982-2012 over Taiwan and Southeast China: Characteristics and possible causes. Int. J. Climatol., 35, 2608-2619, https://doi.org/10.1002/joc.4159.

— , Y. Chang, and P. Huang, 2019: Relationship between the interannual variations of summer convective afternoon rainfall activity in Taiwan and SSTA (Niño3.4) during 1961-2012: Characteristics and mechanisms. Sci. Rep., 9, 9378, https:// doi.org/10.1038/s41598-019-45901-w.

Huffman, G. J., D. T. Bolvin, E. J. Nelkin, D. B. Wolff, R. F. Adler, G. Gu, and E. F. Stocker, 2007: The TRMM Multisatellite 
Precipitation Analysis (TMPA): Quasi-global, multiyear, combined-sensor precipitation estimates at fine scales. J. Hydrometeor., 8, 38-55, https://doi.org/10.1175/JHM560.1.

Johnson, R. H., 2011: Diurnal cycle of monsoon convection. The Global Monsoon System: Research and Forecast, C.-P. Chang et al., Eds., World Scientific Series on Asia-Pacific Weather and Climate, Vol. 5, World Scientific Publishing Company, 257-276, https://doi.org/10.1142/9789814343411_0015.

Kajikawa, Y., and B. Wang, 2012: Interdecadal change of the South China Sea summer monsoon onset. J. Climate, 25, 3207-3218, https://doi.org/10.1175/JCLI-D-11-00207.1.

Kobayashi, S., and Coauthors, 2015: The JRA-55 reanalysis: General specifications and basic characteristics. J. Meteor. Soc. Japan Ser. II, 93, 5-48, https://doi.org/10.2151/JMSJ.2015-001.

Krishnamurti, T. N., and C. M. Kishtawal, 2000: A pronounced continental-scale diurnal mode of the Asian summer monsoon. Mon. Wea. Rev., 128, 462-473, https://doi.org/10.1175/ 1520-0493(2000)128<0462:APCSDM > 2.0.CO;2.

Kuo, H. L., and Q. F. Qian, 1981: Influence of the Tibetan Plateau on cumulative and diurnal changes of weather and climate in summer. Mon. Wea. Rev., 109, 2337-2356, https://doi.org/ 10.1175/1520-0493(1981)109<2337:IOTTPO > 2.0.CO;2.

Kwon, M., J.-G. Jhun, and K.-J. Ha, 2007: Decadal change in East Asian summer monsoon circulation in the mid-1990s. Geophys. Res. Lett., 34, L21706, https://doi.org/10.1029/ 2007 GL031977.

Lau, K. M., M. K. Kim, and K. M. Kim, 2006: Asian summer monsoon anomalies induced by aerosol direct forcing: The role of the Tibetan Plateau. Climate Dyn., 26, 855-864, https:// doi.org/10.1007/s00382-006-0114-z.

Li, P., K. Furtado, T. Zhou, H. Chen, J. Li, Z. Guo, and C. Xiao, 2020a: The diurnal cycle of East Asian summer monsoon precipitation simulated by the Met Office Unified Model at convection-permitting scales. Climate Dyn., 55, 131-151, https://doi.org/10.1007/s00382-018-4368-z.

—, C. Moseley, A. F. Prein, H. Chen, J. Li, K. Furtado, and T. Zhou, 2020b: Mesoscale convective system precipitation characteristics over East Asia. Part I: Regional differences and seasonal variations. J. Climate, 33, 9271-9286, https://doi.org/ 10.1175/JCLI-D-20-0072.1.

Li, Z., and Coauthors, 2016: Aerosol and monsoon climate interactions over Asia. Rev. Geophys., 54, 866-929, https://doi.org/ 10.1002/2015RG000500.

Nitta, T., and S. Yamada, 1989: Recent warming of tropical sea surface temperature and its relationship to the Northern Hemisphere circulation. J. Meteor. Soc. Japan, 67, 375-383, https://doi.org/10.2151/JMSJ1965.67.3_375.

Ohsawa, T., H. Ueda, T. Hayashi, A. Watanabe, and J. Matsumoto, 2001: Diurnal variations of convective activity and rainfall in tropical Asia. J. Meteor. Soc. Japan, 79, 333-352, https:// doi.org/10.2151/jmsj.79.333.

Pan, H., and G. Chen, 2019: Diurnal variations of precipitation over North China regulated by mountain-plains solenoid and boundary-layer inertial oscillation. Adv. Atmos. Sci., 36, 863884, https://doi.org/10.1007/s00376-019-8238-3.

Shapiro, A., E. Fedorovich, and S. Rahimi, 2016: A unified theory for the Great Plains nocturnal low-level jet. J. Atmos. Sci., 73, 3037-3057, https://doi.org/10.1175/JAS-D-15-0307.1.

Shin, U., T.-Y. Lee, and S.-H. Park, 2019: Environment and processes for heavy rainfall in the early morning over the Korean peninsula during episodes of cloud clusters associated with mesoscale troughs. J. Meteor. Soc. Japan, 97, 633-655, https:// doi.org/10.2151/jmsj.2019-036.
Si, D., Y. Ding, and Y. Liu, 2009: Decadal northward shift of the Meiyu belt and the possible cause. Chin. Sci. Bull., 54, 47424748, https://doi.org/10.1007/s11434-009-0385-y.

Song, F., and T. Zhou, 2014a: Interannual variability of East Asian summer monsoon simulated by CMIP3 and CMIP5 AGCMs: Skill dependence on Indian Ocean-western Pacific anticyclone teleconnection. J. Climate, 27, 1679-1697, https://doi.org/ 10.1175/JCLI-D-13-00248.1.

_ and _ 2014b: The climatology and interannual variability of East Asian summer monsoon in CMIP5 coupled models: Does air-sea coupling improve the simulations? J. Climate, 27, 8761-8777, https://doi.org/10.1175/JCLI-D-14-00396.1.

— - , and Y. Qian, 2014: Responses of East Asian summer monsoon to natural and anthropogenic forcings in the 17 latest CMIP5 models. Geophys. Res. Lett., 41, 596-603, https:// doi.org/10.1002/2013GL058705.

Sun, B., and H. Wang, 2015: Inter-decadal transition of the leading mode of inter-annual variability of summer rainfall in East China and its associated atmospheric water vapor transport. Climate Dyn., 44, 2703-2722, https://doi.org/10.1007/s00382-014-2251-0.

Sun, J., and F. Zhang, 2012: Impacts of mountain-plains solenoid on diurnal variations of rainfalls along the mei-yu front over the East China plains. Mon. Wea. Rev., 140, 379-397, https:// doi.org/10.1175/MWR-D-11-00041.1.

Tao, S., and L. Chen, 1987: A review of recent research on the East Asian summer monsoon in China. Monsoon Meteorology, C.-P. Chang and T. N. Krishnamurti, Eds., Oxford Univ. Press, 60-92.

Wang, B., and Z. Fan, 1999: Choice of South Asian summer monsoon indices. Bull. Amer. Meteor. Soc., 80, 629-638, https://doi.org/ 10.1175/1520-0477(1999)080<0629:COSASM>2.0.CO;2.

Wang, C. C., G. T. J. Chen, and R. E. Carbone, 2004: A climatology of warm-season cloud patterns over East Asia based on GMS infrared brightness temperature observations. Mon. Wea. Rev., 132, 1606-1629, https://doi.org/10.1175/1520-0493(2004) 132<1606:ACOWCP $>2.0$.CO;2.

Wang, H., 2001: The weakening of the Asian monsoon circulation after the end of 1970's. Adv. Atmos. Sci., 18, 376-386, https:// doi.org/10.1007/BF02919316.

Wu, B., T. Zhou, and T. Li, 2009: Seasonally evolving dominant interannual variability modes of East Asian climate. J. Climate, 22, 2992-3005, https://doi.org/10.1175/2008JCLI2710.1.

Wu, G., Y. Liu, B. He, Q. Bao, A. Duan, and F. Jin, 2012: Thermal controls on the Asian summer monsoon. Sci. Rep., 2, 404, https://doi.org/10.1038/srep00404.

— , and Coauthors, 2015: Tibetan Plateau climate dynamics: Recent research progress and outlook. Natl. Sci. Rev., 2, 100116, https://doi.org/10.1093/nsr/nwu045.

Wu, R., and L. Chen, 1998: Decadal variation of summer rainfall in the Yangtze-Huaihe River valley and its relationship to atmospheric circulation anomalies over East Asia and western North Pacific. Adv. Atmos. Sci., 15, 510-522, https://doi.org/ 10.1007/s00376-998-0028-2.

Wu, T., and Z. Qian, 2003: The relation between the Tibetan winter snow and the Asian summer monsoon and rainfall: An observational investigation. J. Climate, 16, 2038-2051, https://doi.org/ 10.1175/1520-0442(2003)016<2038:TRBTTW>2.0.CO;2.

Xue, M., X. Luo, K. Zhu, Z. Sun, and J. Fei, 2018: The controlling role of boundary layer inertial oscillations in Meiyu frontal precipitation and its diurnal cycles over China. J. Geophys. Res. Atmos., 123, 5090-5115, https://doi.org/10.1029/2018JD028368.

Yamada, H., B. Geng, H. Uyeda, and K. Tsuboki, 2007: Thermodynamic impact of the heated landmass on the nocturnal evolution of a cloud cluster over a Meiyu-Baiu front. 
J. Meteor. Soc. Japan, 85, 663-685, https://doi.org/10.2151/ JMSJ.85.663.

Yatagai, A., K. Kamiguchi, O. Arakawa, A. Hamada, N. Yasutomi, and A. Kitoh, 2012: APHRODITE: Constructing a long-term daily gridded precipitation dataset for Asia based on a dense network of rain gauges. Bull. Amer. Meteor. Soc., 93, 14011415, https://doi.org/10.1175/BAMS-D-11-00122.1.

Yeh, D., and Coauthors, 1979: Meteorology of the Qinghai-Xizang (Tibet) Plateau (in Chinese). Science Press, 278 pp.

Yu, R., T. Zhou, A. Xiong, Y. Zhu, and J. Li, 2007: Diurnal variations of summer precipitation over contiguous China. Geophys. Res. Lett., 34, L01704, https://doi.org/10.1029/2006GL028129.

Yuan, W., R. Yu, H. Chen, J. Li, and M. Zhang, 2010: Subseasonal characteristics of diurnal variation in summer monsoon rainfall over central eastern China. J. Climate, 23, 6684-6695, https://doi.org/10.1175/2010JCLI3805.1.

,-- , M. Zhang, W. Lin, H. Chen, and J. Li, 2012: Regimes of diurnal variation of summer rainfall over subtropical East Asia. J. Climate, 25, 3307-3320, https://doi.org/10.1175/JCLID-11-00288.1.

,-- , and J. Li, 2013: Changes in the diurnal cycles of precipitation over eastern China in the past 40 years. Adv. Atmos. Sci., 30, 461-467, https://doi.org/10.1007/s00376-012-2092-x.

Zeng, W., G. Chen, Y. Du, and Z. Wen, 2019: Diurnal variations of low-level winds and rainfall response to large-scale circulations during a heavy rainfall event. Mon. Wea. Rev., 147, 39814004, https://doi.org/10.1175/MWR-D-19-0131.1.

Zhai, P., X. Zhang, H. Wan, and X. Pan, 2005: Trends in total precipitation and frequency of daily precipitation extremes over China. J. Climate, 18, 1096-1108, https://doi.org/10.1175/JCLI-3318.1.

Zhang, A., Y. Chen, S. Zhou, C. Cui, R. Wan, and Y. Fu, 2020: Diurnal variation of Meiyu rainfall in the Yangtze Plain during atypical Meiyu years. J. Geophys. Res. Atmos., 125, e2019JD031742, https://doi.org/10.1029/2019JD031742.

Zhang, R., 2015: Changes in East Asian summer monsoon and summer rainfall over eastern China during recent decades. Sci. Bull., 60, 1222-1224, https://doi.org/10.1007/s11434-015-0824-x.
—, A. Sumi, and M. Kimoto, 1996: Impact of El Niño on the East Asian monsoon: A diagnostic study of the '86/87 and ' $91 / 92$ events. J. Meteor. Soc. Japan, 74, 49-62, https://doi.org/ 10.2151/jmsj1965.74.1_49.

Zhang, Y., F. Zhang, C. Davis, and J. Sun, 2018: Diurnal evolution and structure of long-lived mesoscale convective vortices along the mei-yu front over the East China Plains. J. Atmos. Sci., 75, 1005-1025, https://doi.org/10.1175/JASD-17-0197.1.

—, M. Xue, K. Zhu, and B. Zhou, 2019: What is the main cause of diurnal variation and nocturnal peak of summer precipitation in Sichuan Basin, China? The key role of boundary layer lowlevel jet inertial oscillations. J. Geophys. Res. Atmos., 124, 2643-2664, https://doi.org/10.1029/2018JD029834.

Zhou, B., P. Zhai, and Y. Chen, 2020: Contribution of changes in synoptic-scale circulation patterns to the past summer precipitation regime shift in eastern China. Geophys. Res. Lett., 47, e2020GL087728, https://doi.org/10.1029/ 2020GL087728.

Zhou, T., and R. Yu, 2005: Atmospheric water vapor transport associated with typical anomalous summer rainfall patterns in China. J. Geophys. Res., 110, D08104, https://doi.org/10.1029/ 2004JD005413.

, - - H. Chen, A. Dai, and Y. Pan, 2008: Summer precipitation frequency, intensity, and diurnal cycle over China: A comparison of satellite data with rain gauge observations. J. Climate, 21, 3997-4010, https://doi.org/10.1175/2008JCLI2028.1.

— , F. Song, R. Lin, X. Chen, and X. Chen, 2013: The 2012 North China floods: Explaining an extreme rainfall event in the context of a long-term drying tendency [in "Explaining Extreme Events of 2012 from a Climate Perspective"]. Bull. Amer. Meteor. Soc., 94 (9), S49-S51, https://doi.org/10.1175/ BAMS-D-13-00085.1.

Zhu, Y., H. Wang, W. Zhou, and J. Ma, 2011: Recent changes in the summer precipitation pattern in East China and the background circulation. Climate Dyn., 36, 1463-1473, https:// doi.org/10.1007/s00382-010-0852-9. 